\title{
Gadd45g initiates embryonic stem cell differentiation and inhibits breast cell carcinogenesis
}

\author{
Xinbao Zhang ${ }^{1,4}$, Yuting $\mathrm{Li}^{1,4}$, Junxiang $\mathrm{Ji}^{1,4}$, Xin Wang ${ }^{1}$, Meng Zhang ${ }^{1}$, Xiangfen $\mathrm{Li}^{1}$, Yan Zhang ${ }^{1}$, Zhenhua Zhu ${ }^{1}$, \\ Shou-Dong $Y e$ iD $^{1,2,5 \bowtie}$ and Xiaoxiao Wang (iD ${ }^{3,5} \bowtie$
}

(c) The Author(s) 2021

Many self-renewal-promoting factors of embryonic stem cells (ESCs) have been implicated in carcinogenesis, while little known about the genes that direct ESCs exit from pluripotency and regulate tumor development. Here, we show that the transcripts of Gadd45 family genes, including Gadd45a, Gadd45b, and Gadd45g, are gradually increased upon mouse ESC differentiation. Upregulation of Gadd45 members decreases cell proliferation and induces endodermal and trophectodermal lineages. In contrast, knockdown of Gadd45 genes can delay mouse ESC differentiation. Mechanistic studies reveal that Gadd45g activates MAPK signaling by increasing expression levels of the positive modulators of this pathway, such as Csf1r, Igf2, and Fgfr3. Therefore, inhibition of MAPK signaling with a MEK specific inhibitor is capable of eliminating the differentiation phenotype caused by Gadd45g upregulation. Meanwhile, GADD45G functions as a suppressor in human breast cancers. Enforced expression of GADD45G significantly inhibits tumor formation and breast cancer metastasis in mice through limitation of the propagation and invasion of breast cancer cells. These results not only expand our understanding of the regulatory network of ESCs, but also help people better treatment of cancers by manipulating the prodifferentiation candidates.

Cell Death Discovery (2021)7:271; https://doi.org/10.1038/s41420-021-00667-x

\section{INTRODUCTION}

Embryonic stem cells (ESCs) isolated from the inner cell mass of preimplantation blastocysts have two important characteristics, self-renewal and pluripotency [1]. In 1981, Evans and Martin et al. established ESCs in mice for the first time $[2,3]$. The undifferentiated state of mouse ESCs (mESCs) can be maintained under serum-containing medium supplemented with LIF or in serumfree medium by adding 2i, including MEK inhibitor PD0325091 (PD03) and Gsk3 $\beta$ inhibitor CHIR99021 (CHIR) [4-6]. 2i/LIFmediated FGF/MEK/ERK, Wnt/ $\beta$-catenin, and LIF/STAT3 signaling pathways have become important pathways to regulate naïve pluripotency. To date, self-renewal circuitry in mESCs is increasingly defined. Oct3/4, Sox2, and Nanog are the core transcription factors that safeguard the stemness of ESCs [1]. Additionally, many genes with the ability to promote self-renewal have also been identified, such as Tfcp2I1, KIf2, KIf4, and Esrrb [7-11]. Interestingly, many self-renewal genes have a robust function in promoting cancer cell carcinogenesis. For instance, Oct4, Sox2, or Nanog upregulation facilitates the expansion features of breast cancer stem cells and promotes breast cancer tumorigenesis [12-14], and KLF family members have always been recognized as oncogenes in multiple tumors [15]. However, little is known about the mechanism events that drive the differentiation processes of
ESCs, and what is the specific function of them during tumor cell carcinogenesis.

Growth arrest and DNA damage-inducing protein 45 (Gadd45) family members, including Gadd45a, Gadd45b, and Gadd45g, have been implicated in many basic processes, such as DNA repair [16], genome stability [17], epigenetic regulation [18], cell cycle arrest [19], apoptosis [20], tumor development [21], and embryogenesis [22]. Gadd45 proteins are small $(\sim 18 \mathrm{kD})$, with high homology. Gadd45a was the first member identified from Chinese hamster (CHO) cells [23]. Gadd45b was identified as a novel myeloid differentiation primary response gene induced by IL- 6 [24]. Gadd45g was first described as an IL-2-inducible gene [25]. Gadd $45 \mathrm{~g}$ caught our most attention because depletion of Gadd45g cannot disrupt mESC maintenance [26], whereas Gadd45g is increased after Oct4 expression was knocked down [27-29]. In addition, Gadd45g was detected to be expressed in the scattered cells of the extraembryonic ectoderm and continues to increase after gastrulation during embryonic development [30]. Aside, the transcript of Gadd45g is induced in the E9.5 mouse embryos [31], and is important to the primary sex determination [31], testis development [31], initiation of neuronal differentiation [32], and lineage selection of hematopoietic stem cells [33]. Notably, Gadd45g is required for early embryonic cells to exit pluripotency and enter

\footnotetext{
${ }^{1}$ Center for Stem Cell and Translational Medicine, School of Life Sciences, Anhui University, 230601 Hefei, Anhui, P.R. China. ${ }^{2}$ Institute of Physical Science and Information Technology, Anhui University, 230601 Hefei, Anhui, P.R. China. ${ }^{3}$ The First Affiliated Hospital of USTC, Division of Life Sciences and Medicine, University of Science and Technology

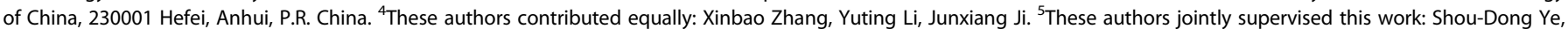
Xiaoxiao Wang. ${ }^{凶}$ email: shdye@126.com; stemxi@126.com

Edited by Dr Ivano Amelio
}

Received: 12 July 2021 Revised: 9 September 2021 Accepted: 22 September 2021

Published online: 02 October 2021 
differentiation in Xenopus [34]. Based on these accumulated data, we speculated that Gadd45g may be a vital determiner for ESCs to initiate the differentiation process.

To validate this hypothesis, we used gain and loss of function methods to investigate the role of Gadd $45 \mathrm{~g}$ in the self-renewal and differentiation of ESCs. Overexpression of Gadd45g decreased cell proliferation and rapidly induced specification of endoderm and trophectoderm in mESCs. Gadd $45 \mathrm{~g}$ functions mainly via activation of MAPK signaling pathway. Importantly, GADD45G suppresses growth and EMT of human breast cancer cells in vivo and vitro and acts as an antitumor character.

\section{RESULTS \\ Enforced Gadd45g instructs mESCs exit from the undifferentiated state}

To investigate the effect of Gadd45g on mESC maintenance, first, we generated a mESC line that overexpressed FLAG-tagged Gadd45g using a PiggyBac vector (PB-Gadd45g) and empty vector (PB) was used as control (Fig. 1A). After cultured in serumcontaining medium in the presence of LIF, PB-Gadd45g mESCs were arrested in G2/M stage and exhibited slower proliferation rate than PB cells (Fig. 1B). To investigate whether Gadd45g overexpression has similar effects in vivo, luciferase-tagged $46 \mathrm{C}$ cells expressing Gadd45g or PB vector were injected into nude mice. The luciferase signal indicated that teratomas was reduced in mice transplanted with the cells expressing Gadd45g compared with mice with the cells expressing PB (Fig. 1C). These results indicate that Gadd $45 \mathrm{~g}$ upregulation suppresses $\mathrm{mESC}$ proliferation.

In addition to a slow growth rate, PB-Gadd45g cells differentiated and exhibited low alkaline phosphatase (AP) activity after two passages, while $\mathrm{PB}$ cells maintained an undifferentiated morphology and sustained high AP activity (Fig. 1D, E). Overexpression of Gadd45g repressed the expression levels of pluripotency genes Esrrb, Nanog, Oct4, and KIf4 (Fig. 1F-H). These data collectively suggest that elevated expression of Gadd45g inhibits the self-renewal ability of mESCs.

As Gadd45g is a robust differentiation driver, we next wanted to decrease its transcription (Gadd45g sh\#1 and Gadd45g sh\#2). The expression levels of Gadd45g were decreased by $\sim 40-60 \%$ compared with the scramble group (Fig. 1I). These cells were grown normally in LIF/serum condition. Subsequently, they were seeded in serum-containing medium without LIF. After 5 days, Gadd45g shRNA mESCs expressed higher levels of self-renewal markers (Tfcp2l1 and Nanog) and generated more AP-positive colonies than scramble cells (Fig. 1J, K). However, both of them became flat and differentiated after 10 days (Fig. 1K). Therefore, downregulation of Gadd $45 \mathrm{~g}$ can delay the differentiation of mESCs.

\section{Overexpression of Gadd $45 \mathrm{~g}$ induces specification of endoderm and trophectoderm in mESCs}

Notably, Gadd45g-overexpressing mESCs quickly became flat, this promotes us to systematically investigate the Gadd45g-induced differentiated cells. As shown in Fig. 2A, PB-Gadd45g mESCs displayed higher levels of endoderm (Foxa2, Sox17, Gata4, and Gata6) and trophectoderm ( $\mathrm{Cdx} 2$ and Elf5) markers than PB cells (Fig. 2A). However, there was no obvious changes in ectoderm (Otx2 and Fgf5) and mesoderm (T and Mixl1) markers (Fig. 2A), indicating that elevated expression of Gadd $45 \mathrm{~g}$ efficiently directs mESCs differentiation into endoderm and trophectoderm cells. Meanwhile, epithelial-mesenchymal transition (EMT) was induced with the emergence of differentiated cells, characterized by the increased levels of EMT associated markers (Zeb1, Zeb2, Snail1, Snail2, Twist1, Mmp9, and Cdh2) and the decreased level of mesenchymal-epithelial transition (MET) marker Cdh1 (Fig. 2B).

Because Gadd45g shares high homology with Gadd45a and Gadd45b, we further planned to investigate whether they have similar effects on mESC maintenance and differentiation. The FLAG-tagged three Gadd45 genes were transduced into $46 \mathrm{C}$ mESCs, respectively (PB-Gadd45a, PB-Gadd45b, and PB-Gadd45g) (Fig. 2C). We observed that PB mESCs maintained an undifferentiated morphology and retained high AP activity grown in LIF/ serum medium, while PB-Gadd45a, PB-Gadd45b, and PB-Gadd45g cells became flat and had low AP activity (Fig. 2D). Accordingly, Gadd45 gene overexpressing mESCs displayed lower level of the pluripotency gene Sox2 (Fig. 2E), whereas expressed higher levels of endoderm (Gata6 and Foxa2), trophectoderm (Cdx2 and Elf5), and EMT (Snail, Twist1, and Cdh2) markers than PB cells (Fig. 2F). These data suggest that all Gadd45 family genes can instruct mESCs exit from the self-renewal state.

To examine the expression patterns of Gadd45 members during $\mathrm{mESC}$ differentiation, $46 \mathrm{C} \mathrm{mESCs}$ were cultured in suspension to form embryoid bodies (EBs) where differentiation proceeds into the three germ layers. The expression of Oct4 was gradually decreased, while the expression levels of Gadd45 family genes and differentiation genes Gata4 and Elf5 were increased at mRNA and protein levels (Figs. 2G and S1), suggesting that Gadd45 family members are closely related to the initiation of $\mathrm{mESC}$ differentiation.

To examine whether Gadd45 genes have cross compensatory functionality in mESCs, we designed two shRNAs (sh\#1 and sh\#2) for each Gadd45 gene to inactive their expression. Stable knockdown of Gadd45 transcript levels was observed (Figure S2A-C). Then, we selected Gadd45a, Gadd45b, and Gadd45g sh\#1 lentiviruses, which have the best gene interference effects, to infect $46 \mathrm{C} \mathrm{mESCs}$ and established Gadd $45 \mathrm{a} / \mathrm{b} / \mathrm{g}$ triple knockdown cell line (Fig. S2D). When cultured in serum-containing medium without LIF for 5 days, Gadd45a/b/g triple knockdown cells generated more AP-positive colonies and expressed higher levels of Tfcp2l1, Nanog, and Oct4 than single Gadd45 gene shRNA cells (Fig. S2E and F). However, all of them differentiated after 10 days (Fig. S2E). These data indicate that there is considerable redundancy among the functions of Gadd45 genes.

\section{Gadd45g activates MAPK signaling pathway}

Compared with Gadd45a and Gadd45b, Gadd45g induced higher levels of differentiation-associated genes when overexpressed but expressed higher levels of self-renewal genes after knockdown (Figs. 2D-F and S2F), we next focused on Gadd45g to understand the mechanism by which Gadd45 gene overexpression suppresses mESC self-renewal. First, high-throughput sequencing was performed to analyze the differently expression genes (DEGs) regulated by $\mathrm{PB}$ and PB-Gadd45g (GEO Number: GSE172474). Compared with $\mathrm{PB}, \mathrm{PB}-\mathrm{Gadd} 45 \mathrm{~g}$ induced 799 upregulated genes and 468 downregulated genes by two folds or greater (Fig. 3A). Second, to gain an insight into how overexpression of Gadd45g induced differentiation, we analyzed the DEGs by KEGG method and found that many candidates are enriched in PI3K/AKT and MAPK signaling pathways (Fig. 3B). MAPK singling is important for mESCs to initiate differentiation [35], we therefore wanted to investigate whether Gadd45g overexpression was engaged in the activation of this pathway. Western blot was carried out to examine the levels of total and phosphorylated RAF1, MEK $1 / 2$, and ERK $1 / 2$ proteins ( $p$-RAF1, $p-M E K 1 / 2$, and $p$-ERK1/2), all of them are the key components of MAPK signaling pathway. Overexpression of Gadd45 genes had no effects on the total protein levels of RAF1, MEK1/2, and ERK1/2, but was able to increase their phosphorylation levels (Fig. 3C, D). In contrast, knockdown of Gadd $45 \mathrm{~g}$ obviously reduced the phosphorylation of MEK $1 / 2$ and ERK1/2 (Fig. 3E). These data indicate that Gadd45g positively mediates the activation of MAPK signaling pathway.

To clarify how Gadd45g stimulates MAPK pathway, we further used qRT-PCR to validate the expression of those 12 candidate genes induced by Gadd45g (Fig. S3), including Pdgfa, Pdgfc, Igf2, Fgfr1, Fgfr3, Erbb2, Erbb3, Epha2, Csf1r, Sos2, Braf, and Cacna1s 

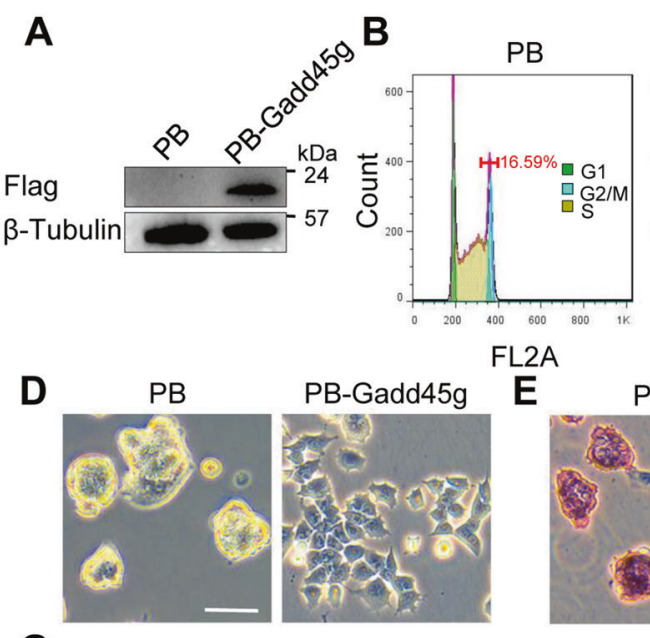

G
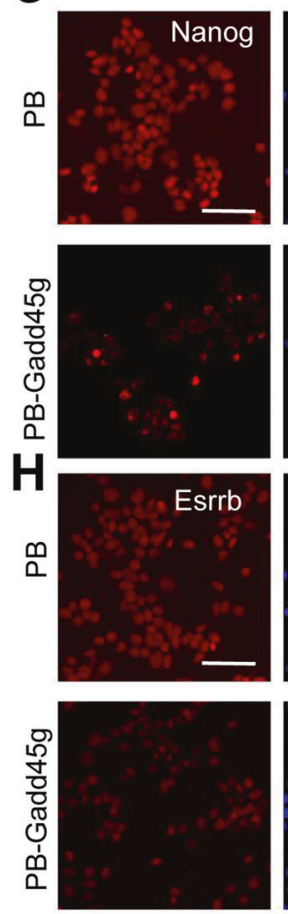

I
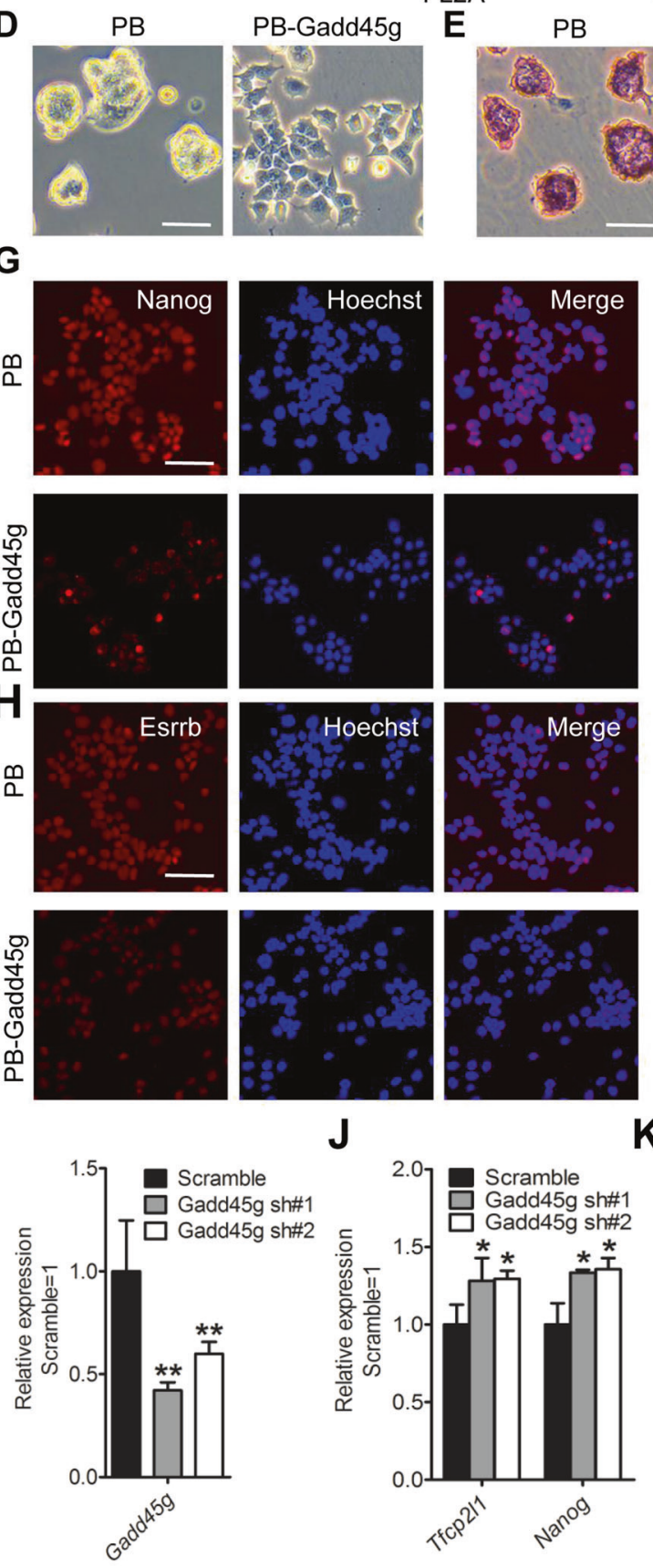

E
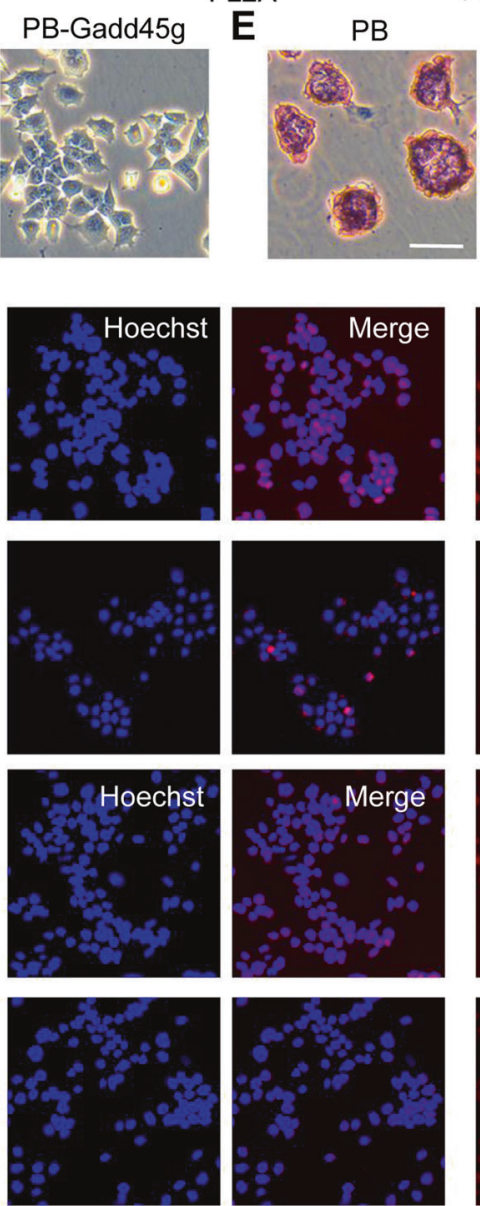

C

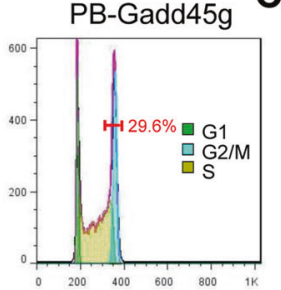

FL2A

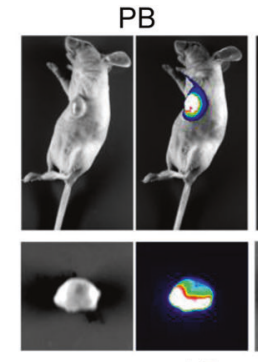

PB-Gadd45g

PB-Gadd45g
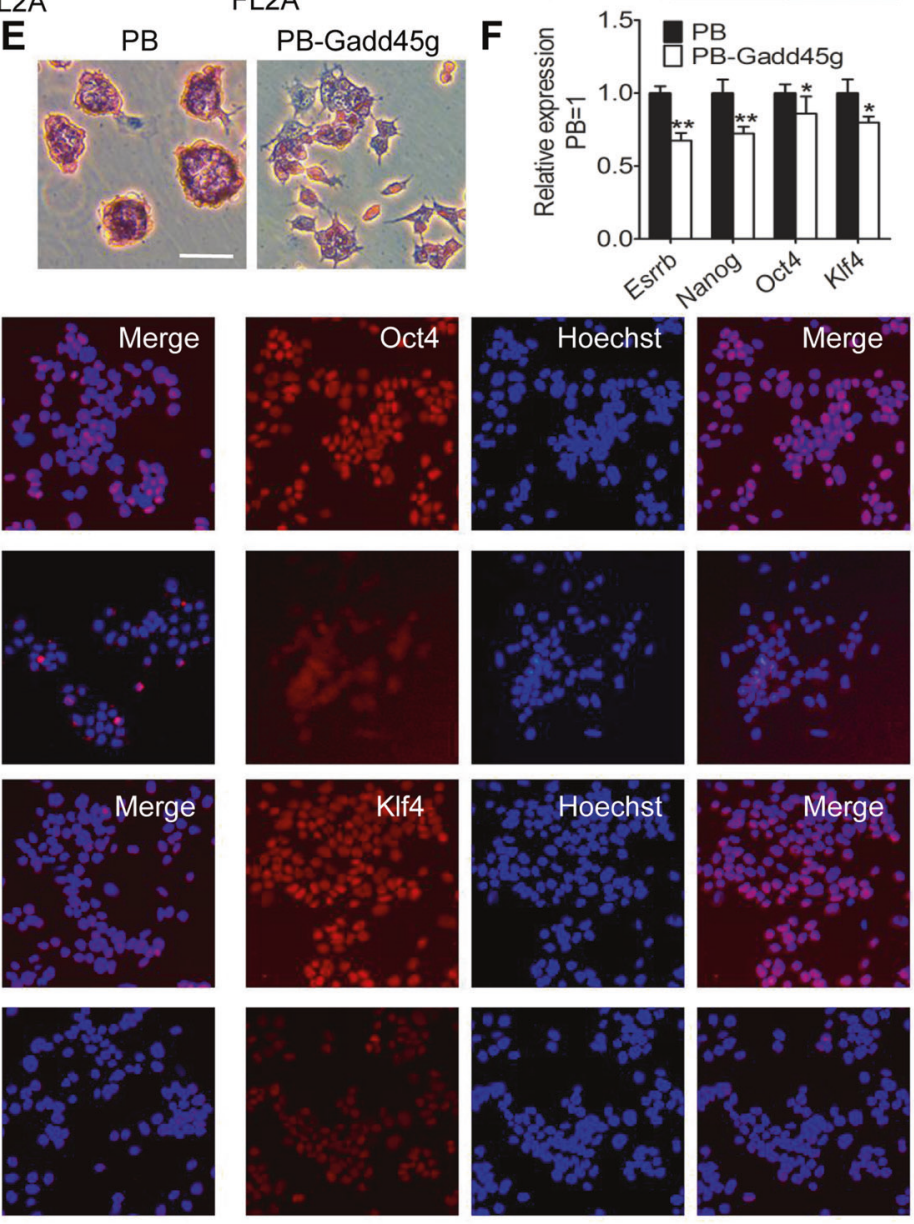

K Scramble

Gadd45g sh\#1 Gadd45g sh\#2
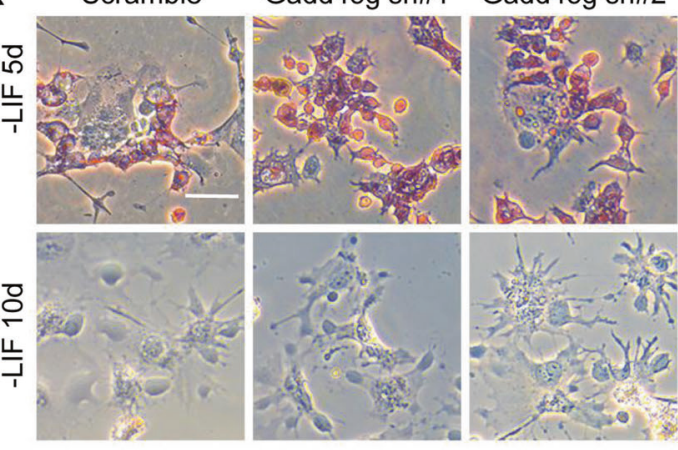

(Fig. 3F and G). At the same time, we also evaluated the expression of these genes in Gadd45a- and Gadd45b-overexpressing mESCs and observed that most of them are significantly induced (Fig. S4). Next, to test whether we can observe opposite expression patterns after Gadd45g was downregulated, we detected the transcripts of these candidates in Gadd45g shRNA cells. Only the transcripts of Igf2, Csf1r, and Fgfr3 are decreased in both two Gadd45g shRNA cell lines (Fig. 3H). To determine whether their transcription is sensitive to Gadd45g upregulation, we used an inducible cassette exchange (ICE) system to generate a mESC line carrying a doxycycline (Dox) inducible Gadd45g transgene (iGadd45g) [36]. Dox treatment could effectively induce the 
Fig. 1 Overexpression of Gadd45g inhibits mESC self-renewal. A Western blot analysis of FLAG in $46 \mathrm{C}$ mESCs overexpressing empty vector (PB) or FLAG-tagged mouse Gadd45g (PB-Gadd45g). $\beta$-tubulin was used as a loading control. B Flow cytometry was used to detect the changes of cell cycle distribution of PB and PB-Gadd45g $46 \mathrm{C} \mathrm{mESCs}$. C Luciferase-tagged $46 \mathrm{C}$ mESCs stably expressing PB or PB-Gadd45g were transplanted in nude mice. The tumors were imaged using Tanon-5200Multi system. D, E Morphology and Alkaline phosphatase (AP) staining of PB and PB-Gadd45g $46 \mathrm{C} \mathrm{mESCs}$ cultured in LIF/serum-containing medium for 2 passages. Bar, $100 \mu \mathrm{M}$. F Quantitative real-time PCR (qRT-PCR) analysis of the expression levels of self-renewal genes Esrrb, Nanog, Oct4, and KIf4. The data are represented as the means \pm s.d. ( $N$ $=3$ biological replicates). ${ }^{*} p<0.05,{ }^{* *} p<0.01$ vs PB. G, $\mathbf{H}$ Immunofluorescence of the expression of pluripotency genes Oct4, Nanog, Esrrb, and KIf4 in PB and PB-Gadd45g $46 \mathrm{C} \mathrm{mESCs.} \mathrm{Bar,} 100 \mu \mathrm{M}$. I qRT-PCR analysis of Gadd45g expression in $46 \mathrm{C}$ mESCs infected with scramble or mouse Gadd45g shRNA lentiviruses (Gadd45g sh\#1 and Gadd45g sh\#2). The data are represented as the means \pm s.d. ( $N=3$ biological replicates). ${ }^{* *} p$ $<0.01$ vs scramble. J qRT-PCR analysis of self-renewal gene expression (Tfcp2l1 and Nanog) in scramble and Gadd45g shRNA mESCs. The data are represented as the means \pm s.d. ( $N=3$ biological replicates). ${ }^{*} p<0.05$ vs scramble. K AP staining of scramble and Gadd $45 \mathrm{~g}$ shRNA $46 \mathrm{C}$ mESCs cultured in serum-containing medium without LIF for 5 days and 10 days. d, days. Bar, $100 \mu \mathrm{M}$.

expression of Gadd45g in i-Gadd45g mESCs (Fig. 3l, J). Subsequently, Dox was supplemented into medium for a short-time treatment and the transcripts of Igf2, Csf1r, and Fgfr3 were increased (Fig. 3K), suggesting that the transcripts of Igf2, Csf1r, and Fgfr3 can quickly be induced in response to Gadd45g upregulation.

\section{Inhibition of MAPK signaling pathway eliminates the lineage commitment induced by Gadd45g}

We further wanted to examine whether blocking this pathway with PD03, a specific MEK inhibitor, can inhibit the phenotype mediated by Gadd45g. As expected, addition of PD03 could efficiently decrease the $p$-ERK $1 / 2$ level in i-Gadd45g mESCs treated with Dox (Fig. 4A), and sufficiently restored the proliferation suppressed by Dox (Fig. 4B). Moreover, i-Gadd45g cells, maintained in LIF/2i condition, expressed higher levels of Oct4 and Nanog and retained stronger AP activity, but displayed lower levels of endoderm and trophectoderm genes (Gata6, Sox17, and Elf5) than LIF/CHIR-treated cells in the presence of Dox (Fig. 4C-E), meaning that Gadd $45 \mathrm{~g}$ upregulation fails to induce differentiation in the presence of PD03 (Fig. 4C-E). The similar results could also be observed in $46 \mathrm{C} \mathrm{mESCs}$ (Fig. S5A and B). Notably, downregulation of Gadd $45 \mathrm{~g}$ was not sufficient to replace the function of PD03 to maintain the undifferentiated state together with CHIR (Fig. S6).

To confirm that PD03 was capable of inhibiting the differentiationassociated EMT phenotype, we checked the changing of cell cytoskeleton with Actin-Tracker Green-488 fluorescent probe and found that the cytoskeleton became stretched and dispersed after Dox was added, whereas addition of PD03 was able to block the EMT induced by Dox (Fig. 4F). Besides, addition of PD03 significantly decreased the expression levels of EMT markers induced by Dox (Fig. 4G). Similar phenotype was observed in 46 C mESCs (Fig. S5C and D). Overall, these results indicate that reduced activity of MAPK pathway is sufficient to repress the differentiation caused by Gadd45g overexpression.

\section{Upregulation of GADD45G inhibits the proliferation of breast cancer cells}

Human induced pluripotent stem cells (iPSCs) have distinguished features with mESCs, whereas overexpression of GADD45G also could lead to human iPSC differentiation (Fig. S7A and B). Notably, in the development of many different kinds of cancers, GADD45G is lowly expressed and is considered to be a functional tumor suppressor (Fig. 5A) [37-39], which is similar to the result we observed in mESCs (Fig. 1B and C). We selected breast cancer cells to do further investigation, as the TCGA database analysis showed that GADD45G is highly expressed in breast cancer patients (Fig. $5 A$ ), implying that GADD45G may be an oncogene. However, the survival curve showed that high level of GADD45G is benefit for the overall survival rate of patients (Fig. 5B). These contradictory results promote us to modulate the transcript of GADD45G to make sure its specific function. FLAG-tagged human GADD45G (PB-GADD45G) and PB were transduced into breast cancer cell lines MCF7 and Hs578T, respectively (Fig. 5C, D). There is no obvious difference in apoptosis between PB and PB-GADD45G breast cancer cells (Fig. S8). The growth of GADD45Goverexpressing MCF7 and Hs578T cells was slower than that of PB cells (Fig. 5E, F). To confirm the proliferation-inhibiting activity of GADD45G in vivo, Luciferase-tagged 4T1, a mouse breast cancer cell line, expressing Gadd $45 \mathrm{~g}$ were established. After transplanted under the breast pads of BALB/C and nude mice, both PB and PBGadd $45 \mathrm{~g}$ cells could generate tumors in mice, while the tumor volumes were reduced derived from Gadd45g cells (Fig. 5G). These data demonstrated that GADD45G overexpression decreases breast cancer cell proliferation.

\section{GADD45G suppresses breast cancer metastasis}

To measure the metastasis-regulating activity of GADD45G, we examined the migration and invasion events with three approaches. First, western blot was performed to detect the levels of EMT makers. As shown in Fig. 6A, B, PB-GADD45G MCF7 and Hs578T cells expressed higher levels of MET maker E-cadherin but exhibited lower level of EMT gene N-cadherin (Fig. 6A, B). Second, transwell assessments showed that MCF7 and Hs578T cells overexpressing GADD45G exhibited decreased invasion capabilities when compared with PB cells (Fig. 6C). Similarly, scratch experiments were used to evaluate the migration of cells, and the results demonstrated that GADD45G had an inhibitory effect on breast cancer migration (Fig. 6D, E). Finally, Luciferase-tagged $4 \mathrm{~T} 1$ cells expressing PB or PB-Gadd45g were also transplanted into $B A L B / c$ and nude mice via tail vein. Mice injected with $\mathrm{PB}$ cells developed more lung metastasis than mice injected with PB-Gadd45g cells (Fig. 6F). These data demonstrate that GADD45G expression suppresses the metastases of breast cancer cells.

\section{DISCUSSION}

The self-renewal markers of ESCs often promote cancer cell proliferation and metastasis. However, the research on ESC differentiation initiation and the effects of differentiationassociated genes on cell carcinogenesis are relatively rare. Our project reveal that Gadd45g upregulation can instruct ESCs exit from undifferentiated state and enter into endoderm and trophectoderm commitment. The MAPK singling pathway is largely responsible for the effect of Gadd45g in mESCs. In addition, GADD45G plays as an antitumor gene and represses proliferation and migration of breast cancer cells in vivo and in vitro (Fig. 6G).

There are several previous reports supporting our findings that Gadd45 family genes are differentiation initiation associated candidates. In situ hybridizations of mouse embryos reveals that Gadd $45 \mathrm{~g}$ is strongly expressed in neuron precursors, Gadd45a expression is enriched in the tip of the closing neural tube and Gadd45b is expressed highly in the chorion [30]. Functional studies reveals that overexpression of Gadd $45 \mathrm{~g}$ not only induces neuronal differentiation of P19 cells [32], but is also critical to 
A

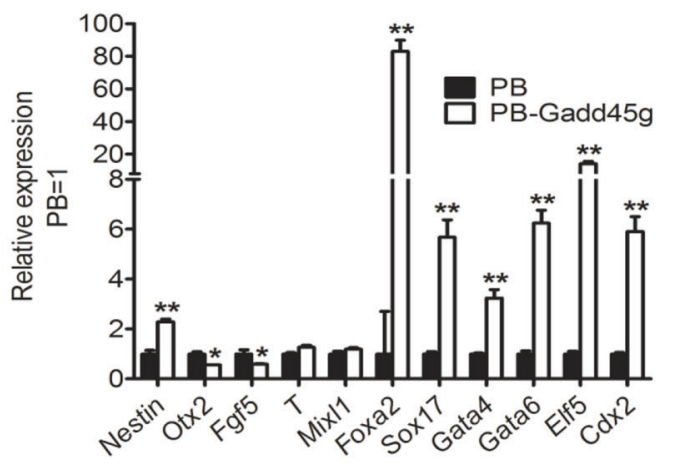

B

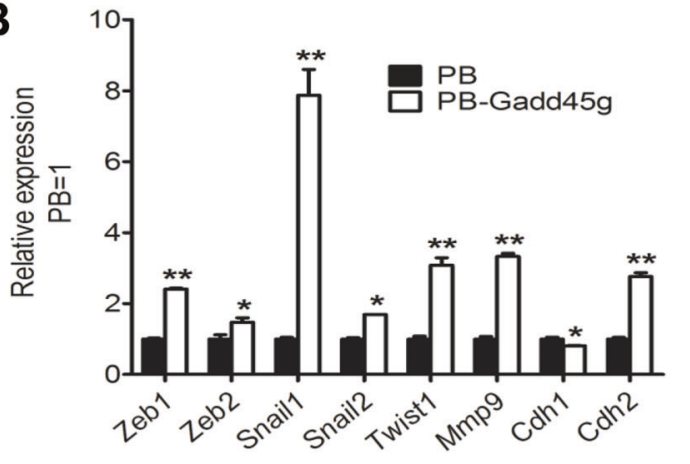

C

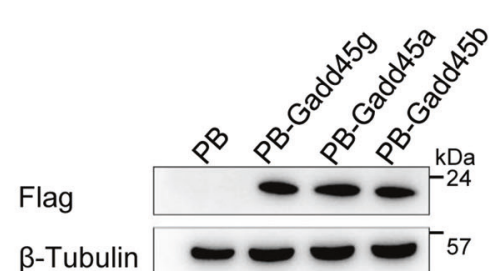

D PB

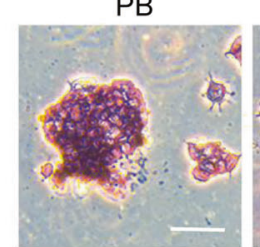

PB-Gadd45g

PB-Gadd45a

PB-Gadd45b
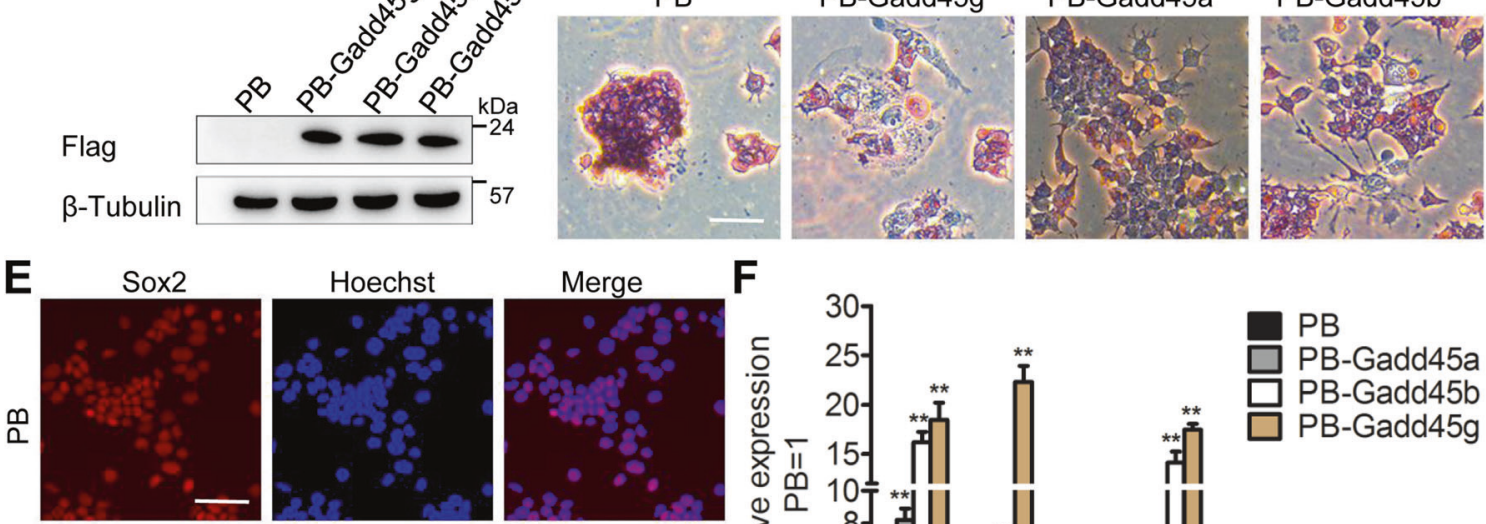

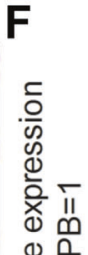
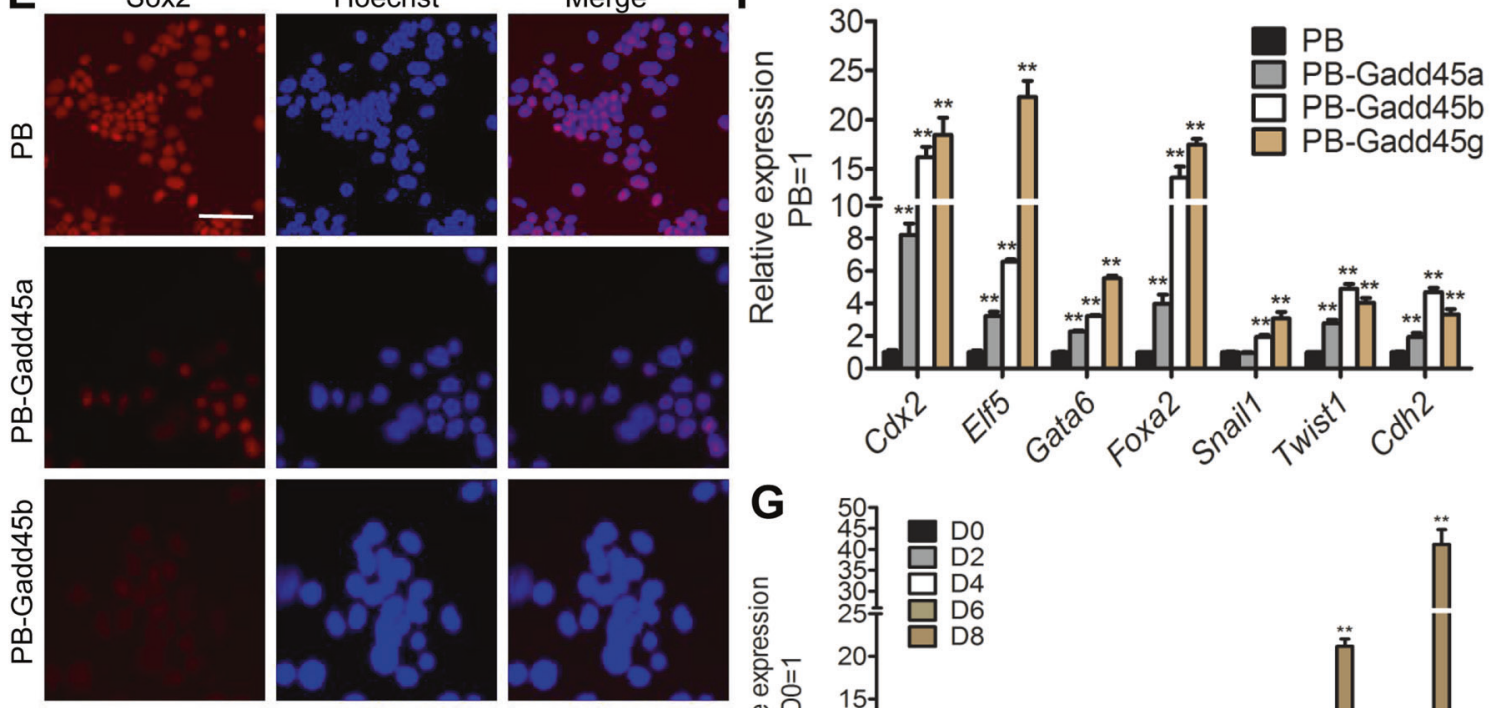

\section{G}
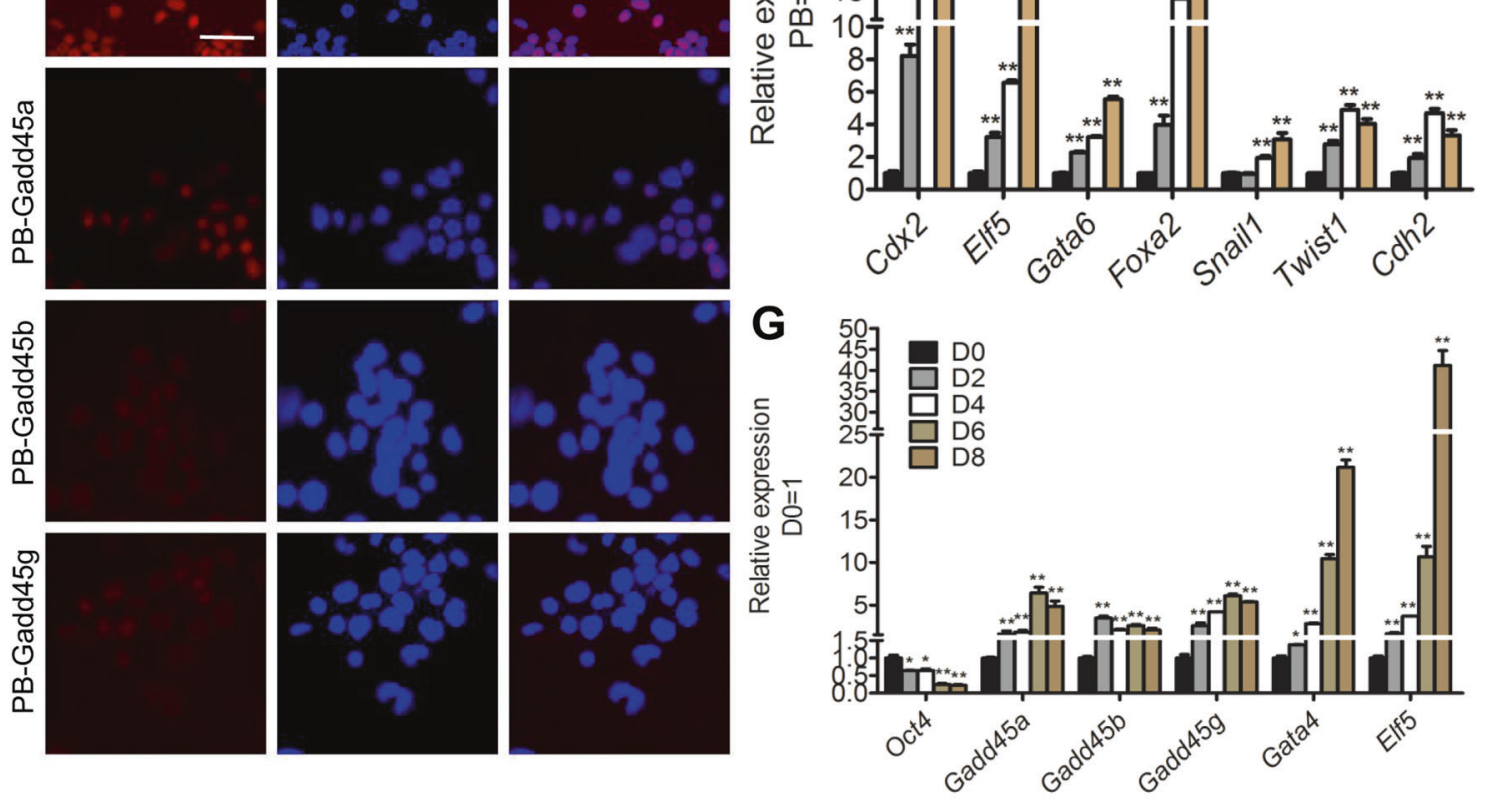

Fig. 2 Overexpression of Gadd45 genes triggers lineage differentiation in mESCs. A qRT-PCR analysis of the expression of specific markers of different germ layers in PB and PB-Gadd $45 \mathrm{~g} 46 \mathrm{C} \mathrm{mESCs}$. The data are represented as the means \pm s.d. ( $N=3$ biological replicates). ${ }^{*} p<0.05$, ${ }^{* *} p<0.01$ vs PB. B qRT-PCR analysis of the expression of epithelial-mesenchymal transition (EMT) marker genes in PB and PB-Gadd45g $46 C$ $\mathrm{mESCs}$ cultured in LIF/serum condition. The data are represented as the means \pm s.d. ( $N=3$ biological replicates). ${ }^{*} p<0.05,{ }^{* *} p<0.01$ vs PB. C Western blot analysis of FLAG in 46 C mESCs overexpressing FLAG-tagged mouse Gadd45 family genes (PB-Gadd45a, PB-Gadd45b, PBGadd45g) or PB. $\beta$-tubulin was used as a loading control. D AP staining of PB, PB-Gadd45a, PB-Gadd45b, and PB-Gadd45g 46 C mESCs cultured in LIF/serum-containing medium for 2 passages. Bar, $100 \mu \mathrm{M}$. E Immunofluorescence of pluripotency gene Sox2 in PB, PB-Gadd45a, PBGadd45b, and PB-Gadd45g $46 \mathrm{C}$ mESCs. Bar, $100 \mu \mathrm{M}$. F qRT-PCR analysis of the expression of differentiation genes and EMT markers in PB, PBGadd45a, PB-Gadd45b, and PB-Gadd45g mESCs cultured in LIF/serum condition. The data are represented as the means \pm s.d. ( $N=3$ biological replicates). ${ }^{* *} p<0.01$ vs PB. G qRT-PCR analysis of mouse Oct4, Gadd45a, Gadd45b, Gadd45g, Gata4, and Elf5 expression levels in 46 C mESCsderived EBs collected from different days. The data are represented as the means \pm s.d. ( $N=3$ biological replicates). ${ }^{*} p<0.05,{ }^{* *} p<0.01$ vs $\mathrm{D} 0$. D0, Day 0. 
A

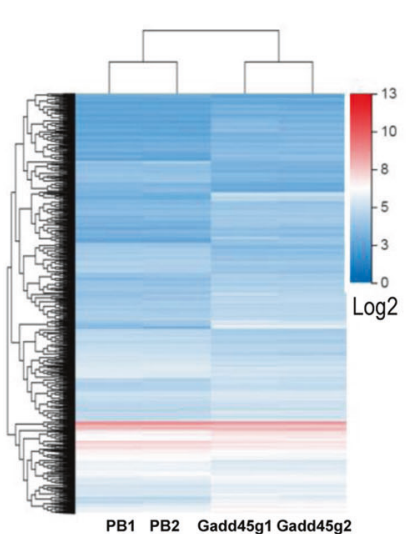

C

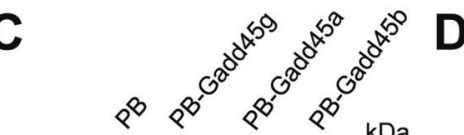

B

PI3K-Akt signaling pathway-

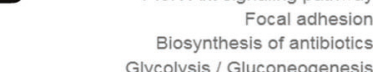

Glycolysis / Gluconeogenesis

Regulation of actin cytoskeleton Biosynthesis of secondary metabolites MAPK signaling pathway Microbial metabolism in diverse environme. Biosynthesis of amino acids Methane metabolism ECM-receptor interaction Carbon metabolism Rap1 signaling pathway FoxO signaling pathway Signaling pathways regulating pluripotenc. Signaling pathways regulating pluripotenc... Chloroalkane and chloroalkene degradation... Estrogen signaling pathway p53 signaling pathway Circadian rhythm - fly -
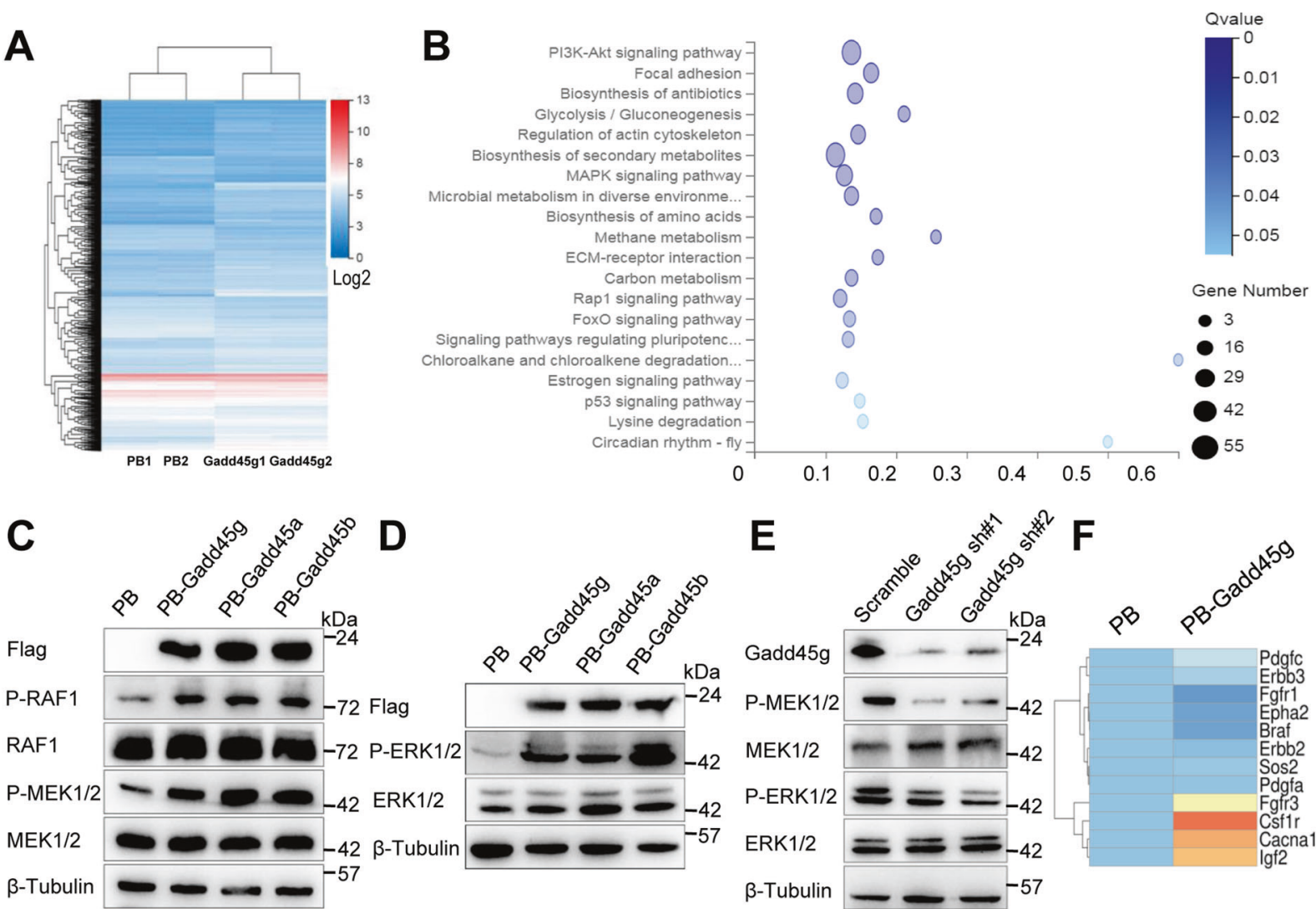

E

G

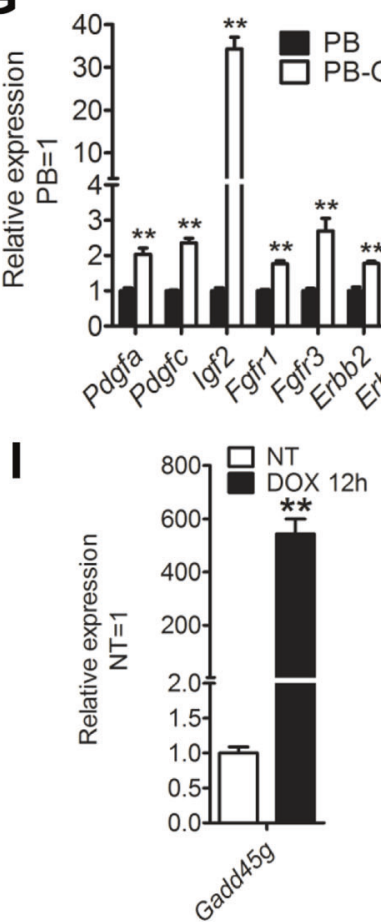

H
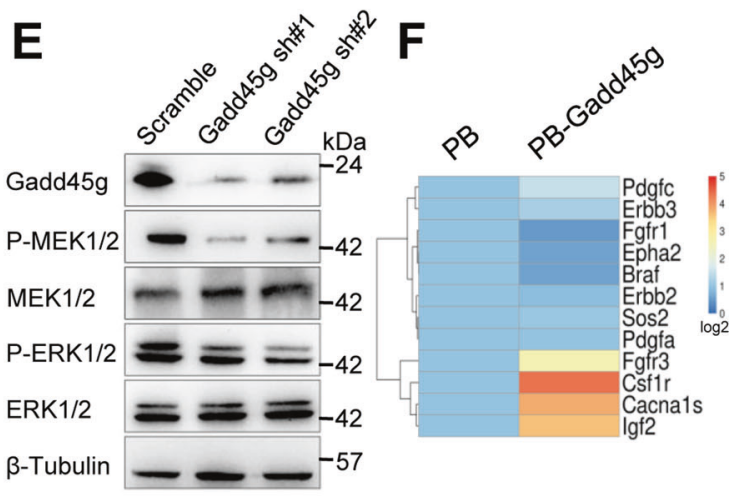

Xenopus and medaka fish embryos exit from pluripotency and enter neural development progress [34, 40, 41]. These data indicate that the role of Gadd45g in the early neuro-directed differentiation of different species is conserved. However, overexpression of Gadd $45 \mathrm{~g}$ induced endoderm and trophectoderm lineage cells in mESCs (Figs. 1D, E and 2A); that may be due to the presence of serum, which can completely block the neural differentiation of mESCs [42]. In addition, Gadd $45 \mathrm{a} / \mathrm{b} / \mathrm{g}$ triple gene knockout mESCs can be established in vitro [26]. Knockdown of Gadd $45 \mathrm{~g}$ could delay differentiation (Fig. 1J, K). Additionally, the transcript level of Gadd $45 \mathrm{~g}$ was increased upon mESC differentiation (Fig. 2G and S1) [26, 27], meaning that Gadd45g is 
Fig. 3 Gadd45g promotes mESC differentiation through activation of MAPK signaling pathway. A Heatmap showing the expression patterns of PB and PB-Gadd45g $46 \mathrm{C}$ mESCs. Genes were ranked according to the level of log2-fold change. B The KEGG analysis of the DEGs regulated by Gadd45g. C Western blot analysis of FLAG, RAF1, P-RAF1, MEK1/2, and P-MEK1/2 in 46 C mESCs overexpressed Gadd45 genes or PB. $\beta$-tubulin was used as a loading control. D Western blot analysis of FLAG, ERK1/2, and P-ERK1/2 levels in Gadd45 genes overexpressing $46 \mathrm{C}$ mESCs. $\beta$-tubulin was used as a loading control. E Western blot analysis of Gadd45g, MEK1/2, P-MEK1/2, ERK1/2, and P-ERK1/2 levels in scramble and Gadd45g shRNA $46 \mathrm{C} \mathrm{mESCs}$ cultured in LIF/serum medium. $\beta$-tubulin was used as a loading control. $\mathbf{F}$ Heatmap showing the DEGs upregulated by Gadd45g and associated with the MAPK signaling pathway. Genes were ranked according to the level of log2-fold change. G qRT-PCR analysis of the expression of candidates showed in panel $\mathbf{F}$. The data are represented as the means \pm s.d. $(N=3$ biological replicates). ${ }^{* *} p<0.01$ vs PB. H qRT-PCR analysis of the expression of the indicated genes (showed in panel F) and Gadd45g in the scramble and Gadd45g shRNA $46 \mathrm{C} \mathrm{mESCs}$ cultured in LIF/serum medium. The data are represented as the means $\pm \mathrm{s} . \mathrm{d}$. ( $N=3$ biological replicates). ${ }^{*} p$ $<0.05,{ }^{*} p<0.01$ vs scramble. I qRT-PCR analysis of Gadd45g expression level in i-Gadd45g mESCs treated with or without Dox for $12 \mathrm{~h}$. The data are represented as the means \pm s.d. ( $N=3$ biological replicates). ${ }^{* *} p<0.01$ vs NT. NT no treatment. J Western blot analysis of Gadd45g levels in i-Gadd45g ESCs cultured in the presence or absence of $2 \mu \mathrm{g}$ Dox. $\beta$-tubulin was used as a loading control. K qRT-PCR analysis of expression levels of Gadd45g, Csf1r, Igf2, and Fgfr3 in i-Gadd45g ESCs treated with Dox for 1 or $2 \mathrm{~h}$. The data are represented as the means $\pm \mathrm{s}$. d. ( $N=3$ biological replicates). ${ }^{*} p<0.05,{ }^{* *} p<0.01$ vs - DOX.

dispensable for mESC maintenance but associated with the differentiation initiation. Moreover, the transcript of Gadd45g is essential for the normal progress of EMT occur in rabbit early embryos [43]. The similar effect of Gadd45 genes on EMT transition can be observed in mESCs (Fig. 2B, F). EMT transition are closely with the ESC differentiation [44-47]. Inhibition of EMT favors the self-renewal of ESCs [47, 48]. Finally, we found that upregulation of Gadd45g activates MAPK signaling pathway (Fig. 3C, D), which is essential for the spontaneous differentiation of mESCs [35]. In contrast to mESCs, human iPSCs and ESCs rely on MAPK signaling to sustain stemness [49]. Interestingly, upregulation of GADD45G induced human iPSC differentiation (Fig. S7B), implying that there are other mechanisms downstream of GADD45G to negatively regulate the pluripotency of human pluripotent stem cells, like DNA demethylation [26].

Another point is that GADD45G significantly inhibits the migration and invasion of breast cancer cells (Fig. 6C-F). Actually, the antitumor activity of GADD45G has been investigated before. Its transcriptional downregulation was frequently found in many tumor cells, including Hodgkin's lymphoma, nasopharyngeal carcinoma, cervical carcinoma, esophageal carcinoma, and lung carcinoma [39]. The decreased levels may be due to the hypermethylation of the proximal promoter of GADD45G $[39,50]$. Ectopic expression of GADD45G not only robustly elicits cellular senescence evasion [37], but also interacts with E-cadherin to enhance its membrane level [51]. We also observed increased E-cadherin protein in response to GADD45G upregulation (Fig. 6A). Additionally, overexpression of GADD45G has ability to restrict proliferation by accumulation of cells arrested in the different stages of cell cycle through association with p21 and cyclin B [5256]. Due to high homology of GADD45 genes, GADD45A and GADD45G exert similar effects on the development of cancers $[54,57,58]$. In this study, we demonstrated that Gadd45g could activate MAPK pathway (Fig. 3B-E). High ERK protein expression levels have been shown to correlate with shorter survival in TripleNegative Breast Cancer Patients [59,60], implying that there are other mechanisms excepted MAPK signaling responsible for effect of GADD45G on the development of breast cancer. However, whether GADD45 family genes share a common set of mechanisms to inhibit the migration and invasion of different cancer cells, more experiments are required to be performed.

In summary, our study demonstrates that Gadd45 genes are pivotal factors involved in the lineage commitment of ESCs. We further demonstrated that MAPK pathway is a major signaling responding to Gadd45g upregulation to direct mESCs exit from self-renewal and enter into the endoderm and trophectoderm cell fates. Meanwhile, GADD45G plays a critical role in inhibiting breast cancer cell migration and invasion. Our research not only demonstrated Gadd45g as a pivotal differentiation inducer of ESCs, but also will help people explore more drugs to better control cell differentiation and cancer treatment.

\section{MATERIALS AND METHODS Cell culture}

46C mESCs, kindly provide by professor Qi-Long Ying (University of Southern California), were seeded on $0.1 \%$ gelatin-coated cell culture plates at $37{ }^{\circ} \mathrm{C}$ in an incubator supplemented with $5 \%$ carbon dioxide. The composition of the mESC basic medium is DMEM (2122149, Biological Industries, Israel) supplemented with 10\% FBS (FND500, ExCell Bio, Australia), 1× MEM nonessential amino acids (N1250, Solarbio, China), $0.1 \mathrm{mM} \beta$-mercaptoethanol (M3148, Sigma), and $1000 \mathrm{U} / \mathrm{ml}$ LIF (LIF1010, Millipore, USA). i-Gadd45g mESCs were maintained in basic medium supplemented with PD0325901 (1 $\mu \mathrm{M}, \mathrm{HY}-10254$, MedChemExpress) and CHIR99021 (3 $\mu \mathrm{M}, \mathrm{HY}-10182$, MedChemExpress). Human transgenes-free induced pluripotent stem cells were kindly provided by NuwaCell.Ltd, China (ZSSY-001) and were cultured in ncTarget medium (RP01020, NuwaCell.Ltd, China). MCF7 and Hs578T cells were purchased from the National Collection of Authenticated Cell Cultures (Chinese Academy of Sciences) and were cultured in DMEM medium supplemented with $10 \%$ FBS.

\section{Plasmid construction}

The coding regions of mouse and human Gadd $45 \mathrm{~g}$ were amplified by PCR and were inserted into PggyBac transposon vectors. For RNA interference (RNAi) in mESCs, small hairpin RNA (shRNA) constructs were designed to target gene-specific regions of Gadd45a, Gadd45b, and Gadd45g and then were cloned into pLKO.1-TRC (\#10878, Addgene). The primer sequences used have been listed in Tables S1 and S2.

\section{Alkaline phosphatase (AP) activity assay}

The cells were fixed in $4 \%$ paraformaldehyde at room temperature for 2 min, after washed twice with PBS, cells were incubated in AP staining reagent (C3206, Beyotime Biotechnology, China) at room temperature for $30 \mathrm{~min}$ in the dark. After washing twice with PBS, we observed and took pictures under the Leica DMI8 microscope.

\section{Western blot}

Cells were lysed in ice-cold RIPA cell buffer (P0013B, Beyotime Biotechnology, China) supplemented with protease inhibitors cocktail. The protein samples were then separated on a $10 \%$ - or $15 \%$-PAGE gel and electrotransferred to a PVDF membrane. After blocking, the membrane was incubated with specific primary antibodies overnight at $4{ }^{\circ} \mathrm{C}$ and followed by a HRP-conjugated secondary antibody at room temperature. Images were captured under the Chemiluminescence Gel Imaging System Tanon-5200Multi (Shanghai Tianneng, China). The primary antibodies are FLAG (SG110-26, GNI, Japan, 1:1000), Nanog (14295-1-AP, Proteintech, USA, 1:1000), Gadd45g (SC-33173, Santa Cruz, USA, 1:500), Gadd45a (UPA06635, Gene Universal, China, 1:500), Gadd45b (UPA01987, Gene Universal, China, 1:500), MEK1/2 (380797, ZENBIO, China, 1:1000), Phospho-MEK1/2 (Ser217/221) (310050, ZENBIO, China, 1:1000), ERK1/2 (201245-4A4, ZENBIO, China, 1:500), PhosphoERK1 (Thr202/Tyr204)/ERK2 (Thr185/Tyr187) (301245, ZENBIO, China, 1:500), Raf1 (251817, ZENBIO, China, 1:1000), Phospho- Raf1 (Ser338) (D155090, BBI, China, 1:1000), $\beta$-tubulin (200608, ZENBIO, China, 1:2000), E-cadherin (201283, ZENBIO, China, 1:1000), and N-cadherin (383341, ZENBIO, China, 1:1000). 
A

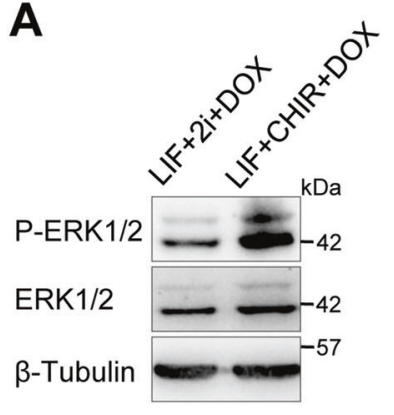

D

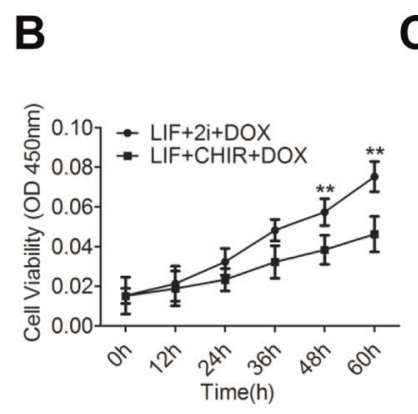

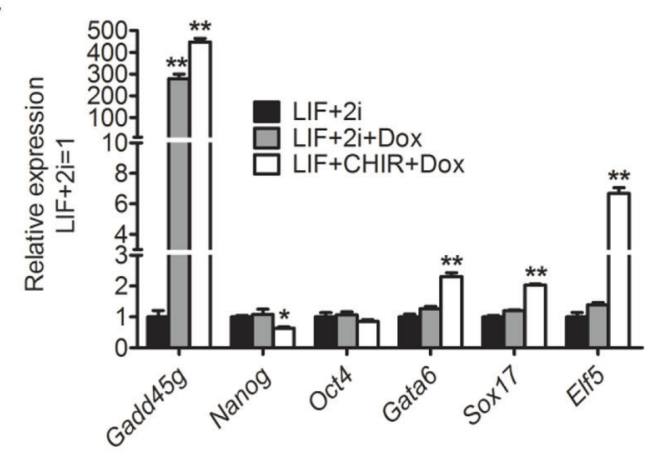

$\mathbf{E}$
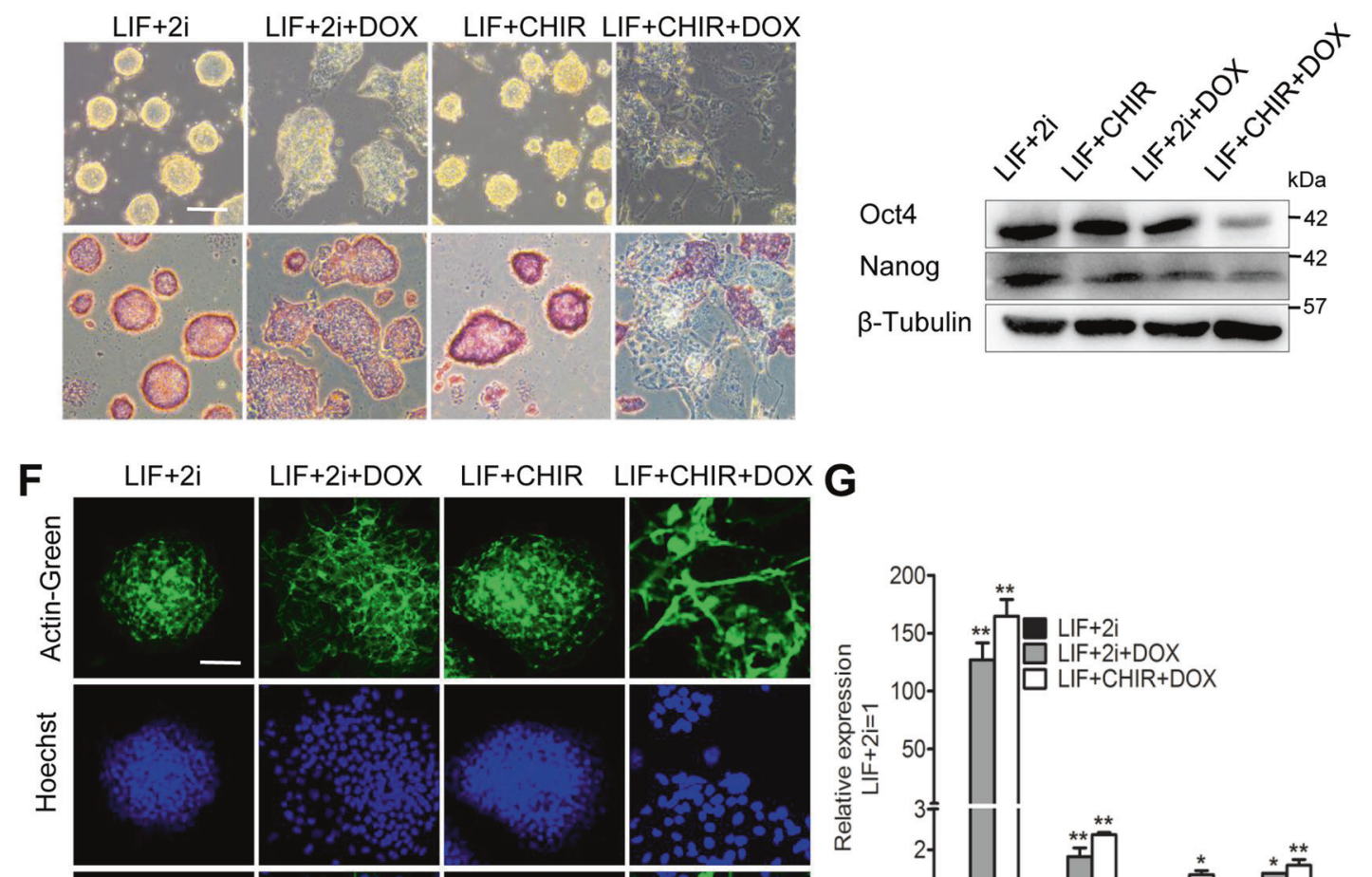

\section{G}

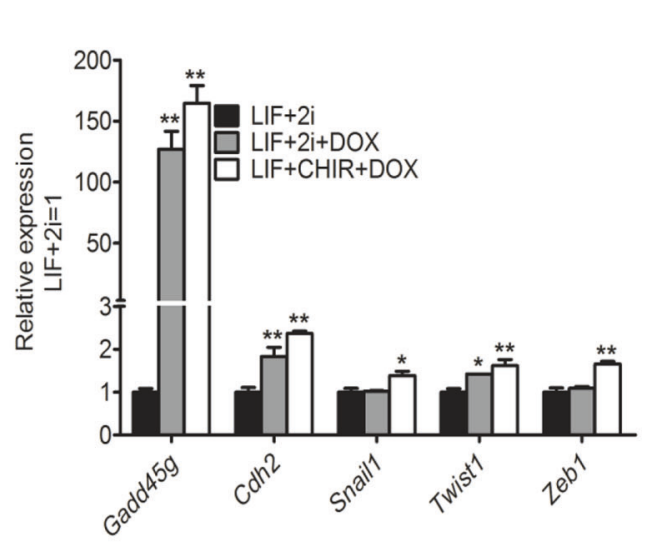

Fig. 4 Suppression of the MAPK signaling pathway inhibits differentiation caused by Gadd45g overexpression. A Western blot analysis of ERK1/2 and P-ERK1/2 levels in i-Gadd45g ESCs cultured in LIF/CHIR/Dox condition in the presence or absence of PD03. $\beta$-tubulin was used as a loading control. B The CCK8 assay was performed to analyze the proliferation of i-Gadd45g ESCs cultured in LIF/CHIR/Dox condition in the presence or absence of PD03. The data are represented as the means \pm s.d. ( $N=3$ independent biological experiments). ${ }^{* *} p<0.01$ vs LIF + CHIR + Dox. C qRT-PCR analysis of Gadd45g, self-renewal (Oct4 and Nanog) and differentiation (Gata6, Sox17, and Elf5) gene expression levels in i-Gadd45g ESCs cultured in the indicated conditions. The data are represented as the means \pm s.d. $\left(N=3\right.$ biological replicates). ${ }^{*} p<0.05,{ }^{* *} p$ $<0.01$ vs LIF +2 i. D Morphology and alkaline phosphatase (AP) staining of i-Gadd45g ESCs cultured in the indicated conditions. Bar, $100 \mu$ M. $E$ Western blot analysis of Oct4 and Nanog protein levels in i-Gadd45g ESCs cultured in the indicated conditions. $\beta$-tubulin was used as a loading control. F Actin-Tracker Green-488 fluorescent probe staining of i-Gadd45g ESCs cultured in the indicated conditions. Bar, $100 \mu \mathrm{M}$. G qRT-PCR analysis of the expression levels of Gadd $45 \mathrm{~g}$ and EMT marker genes in i-Gadd45g ESCs cultured in the indicated conditions. The data are represented as the means \pm s.d. ( $N=3$ biological replicates). ${ }^{*} p<0.05,{ }^{* *} p<0.01$ vs LIF $+2 \mathrm{i}$.

\section{Quantitative real-time PCR (qRT-PCR)}

According to the manufacturer's protocol, the TRIzol Up Plus RNA Kit (R0027, Beyotime, China) was used to isolate total RNA from cells. cDNA was synthesized from $1 \mu \mathrm{g}$ of total RNA with the Hifair III 1st Strand CDNA Synthesis SuperMix for qPCR (11141ES60, YEASEN, China). mRNA expression levels were determined using the Hieff qPCR SYBR Green Master Mix (11201ES08, YEASEN, China) in a PikoReal Real-Time PCR machine (Thermo Scientific, USA). The relative expression level was determined by the $2-\Delta \mathrm{Cq}$ method and normalized to mouse RPL19 expression. The primers used are listed in Table S3.

\section{Immunofluorescence staining}

The cells were fixed in $4 \%$ paraformaldehyde for $30 \mathrm{~min}$ and then were washed twice with PBS. After incubated for $2-3 \mathrm{~h}$ in blocking buffer containing $5 \%$ BSA and $0.2 \%$ Triton X-100, the cells were probed with the 


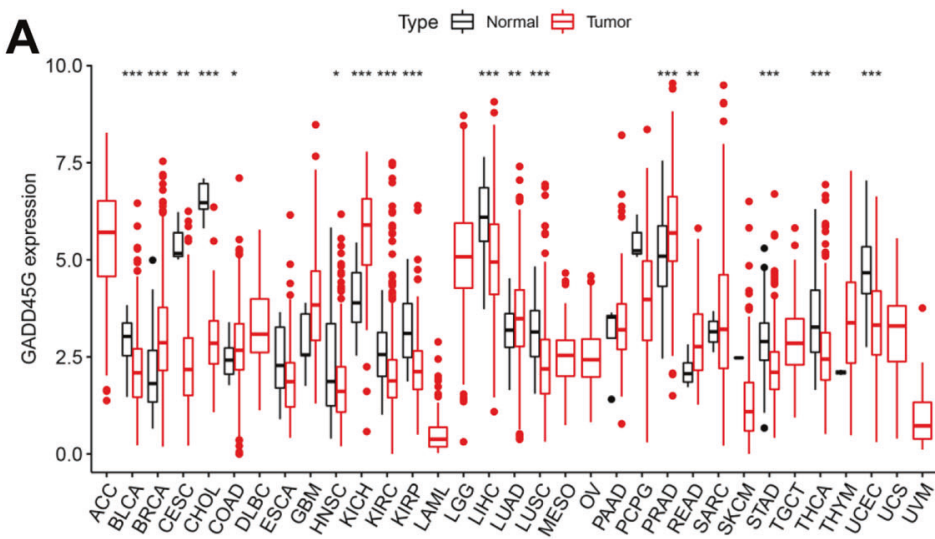

B
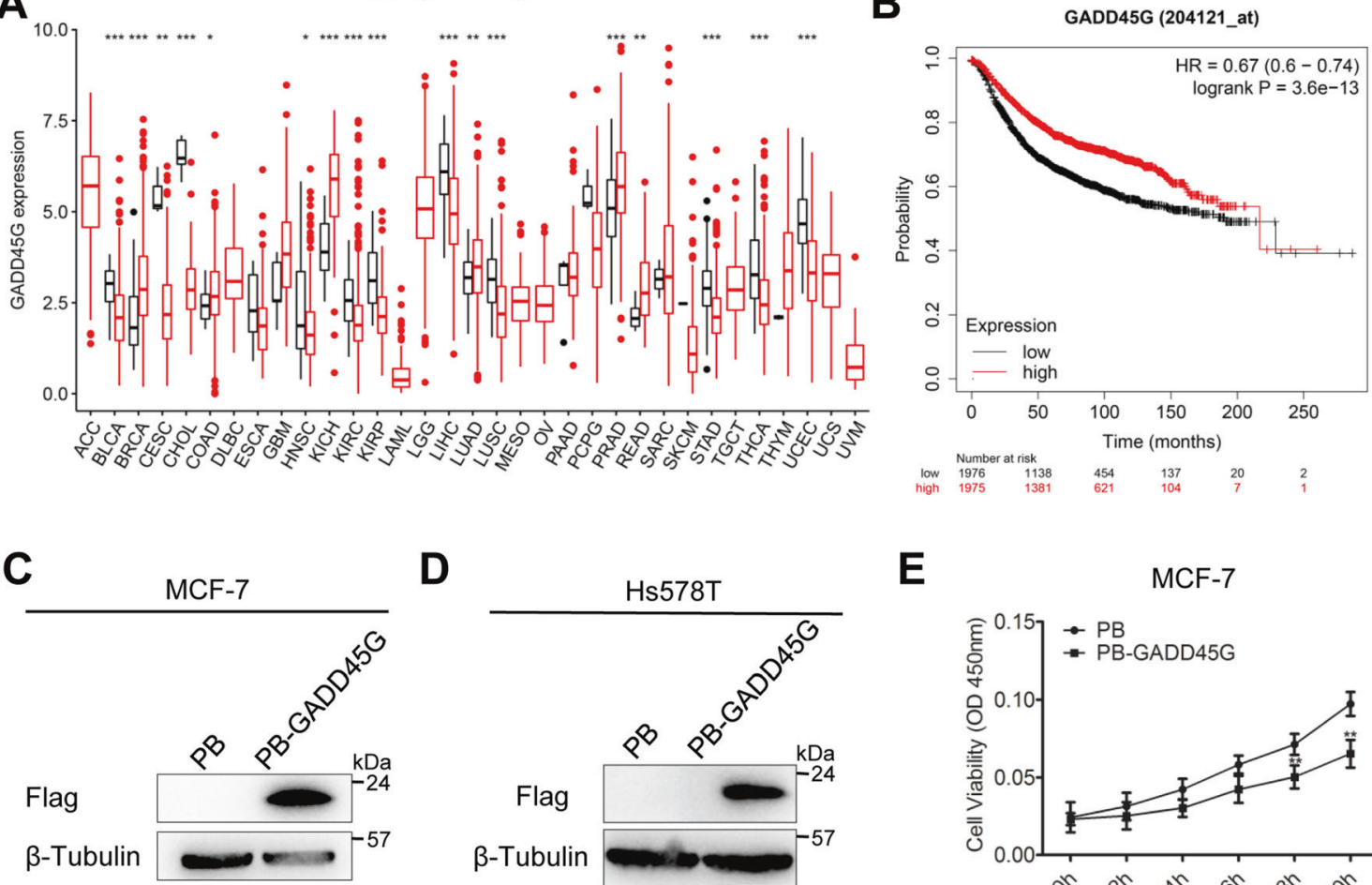

D

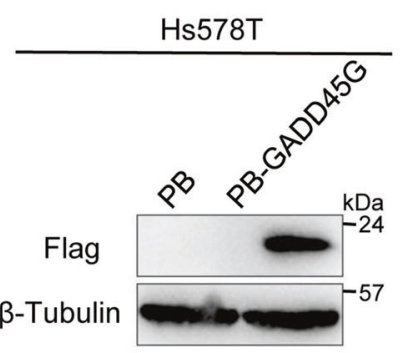

E

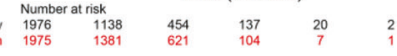

$\mathbf{F}$

Hs578T

G

4T1
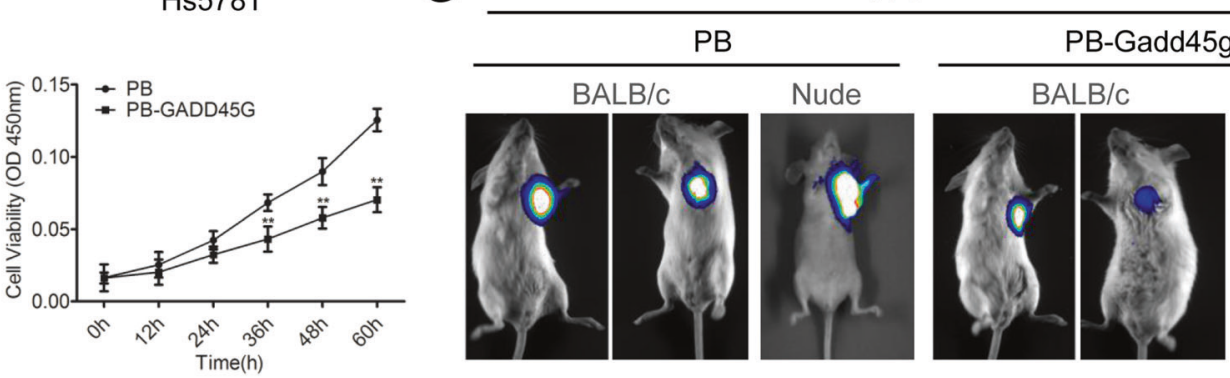

MCF-7

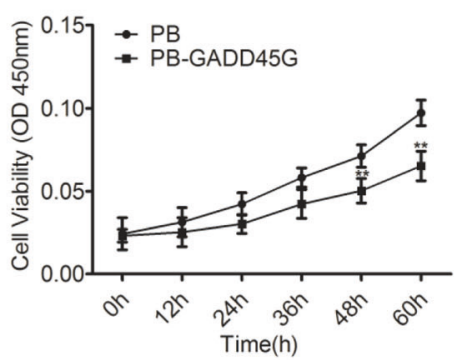

Fig. 5 Overexpression of GADD45G limits the propagation of breast cancer cells. A Analysis of GADD45G expression in different kinds of normal and cancer samples from TCGA database. B The expression level of GADD45G is related to the overall survival time of breast cancer patients. C, D Western blot analysis of FLAG in MCF7 and Hs578T cells overexpressing FLAG-tagged human GADD45G (PB-GADD45G) or empty vector. $\beta$-tubulin was used as a loading control. E, F CCK8 assay was performed to assay the effects of GADD45G on the proliferation of MCF7 and Hs578T cells. The data are represented as the means \pm s.d. ( $N=3$ independent biological experiments). ${ }^{* *} p<0.01$. G Luciferasetagged mouse breast cancer cell line $4 \mathrm{~T} 1$ stably expressing PB or PB-Gadd45g were transplanted in BALB/c and nude mice. Luciferase signals were captured by Tanon-5200Multi system.

primary antibodies overnight at $4{ }^{\circ} \mathrm{C}$. After washed three times with PBS, cells were incubated in blocking buffer containing a specific fluorescent secondary antibody and Hoechst $33342(\mathrm{H} 3570$, Invitrogen, 1:10,000) at $37^{\circ} \mathrm{C}$ for $1 \mathrm{~h}$. The cells were photographed under a Leica DMI8 microscope. The primary antibodies are Oct4 (SC-5279, Santa Cruz, USA, 1:500), Nanog (14295-1-AP, Proteintech, 1:500), Klf4(381633, ZENBIO, China, 1:500), and Sox2 (66411-1-lg, Proteintech, 1:500).

\section{Cell transfection and infection}

For gene overexpression, cells were transfected with $2 \mu \mathrm{g}$ PiggyBac along with $2 \mu \mathrm{g}$ transposase vector using Hieff Trans ${ }^{\mathrm{TM}}$ Liposomal Transfection Reagent (40802ES03, YEASEN, China) according to the manufacturer's instruction. For knockdown experiments, pLKO.1-TRC-based lentiviral vectors and packaging plasmids pMD2.G and psPAX2 were cotransfected into $293 \mathrm{FT}$ cells. The virus supernatant was collected after $48 \mathrm{~h}$ of transfection and was filtered with a $0.45 \mu \mathrm{m}$ filter membrane. Then the viral supernatant was added into the culture medium to infect cells. After $48 \mathrm{~h}$, cells were selected by adding Puromycin, Blasticidin, or Hygromycin.

\section{Embryoid bodies (EB) differentiation}

In order to verify the relationship between Gadd45 genes and mESC differentiation, $5 \times 10^{6} \mathrm{mESCs}$ were cultured in $20 \% \mathrm{FBS}$ in $10 \mathrm{~cm}$ petri dish to form embryoid bodies (EBs), which were collected and lysed in TRIzol or RIPA every two days.

\section{Transwell assay}

The cells were digested by trypsin into single cells and then were counted by Countess 3 (Invitrogen). Six thousands cells were resuspended in DMEM without FBS and then were put into the transwell upper chamber. Next, the normal serum-containing medium was put into the 24-well plate below the chamber. After incubation for $24-48 \mathrm{~h}$, the nonmigrated cells were erased by a cotton swab. The migrated cells were fixed with methanol and were stained with $0.1 \%$ crystal violet. The images were taken with a Leica DMI8 microscope.

\section{Flow cytometry}

The cells were collected, centrifuged, and washed with precooled PBS for three times. Subsequently, $70 \%$ precooled ethanol was used to fix the cells 
A

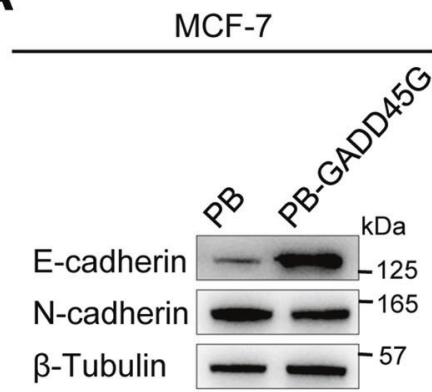

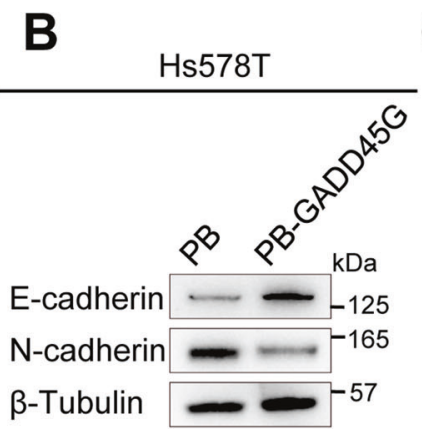

C

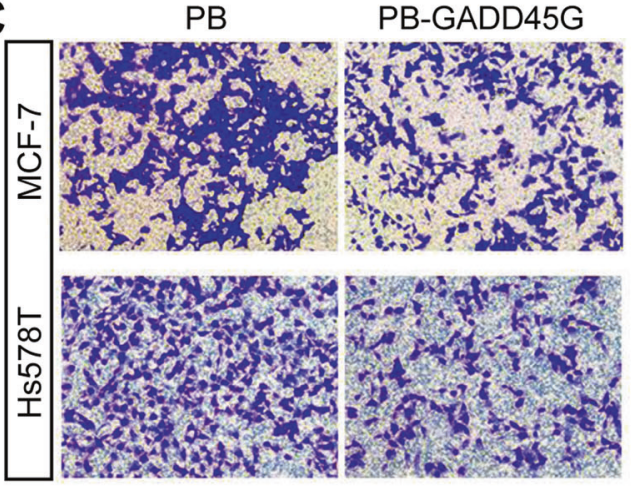

E

MCF-7

D

PB PB-GADD45G
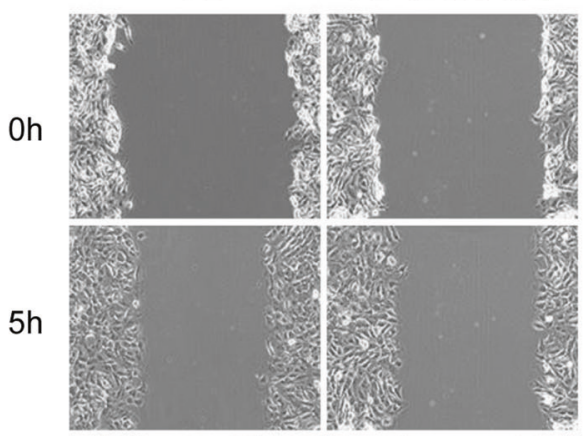

Oh
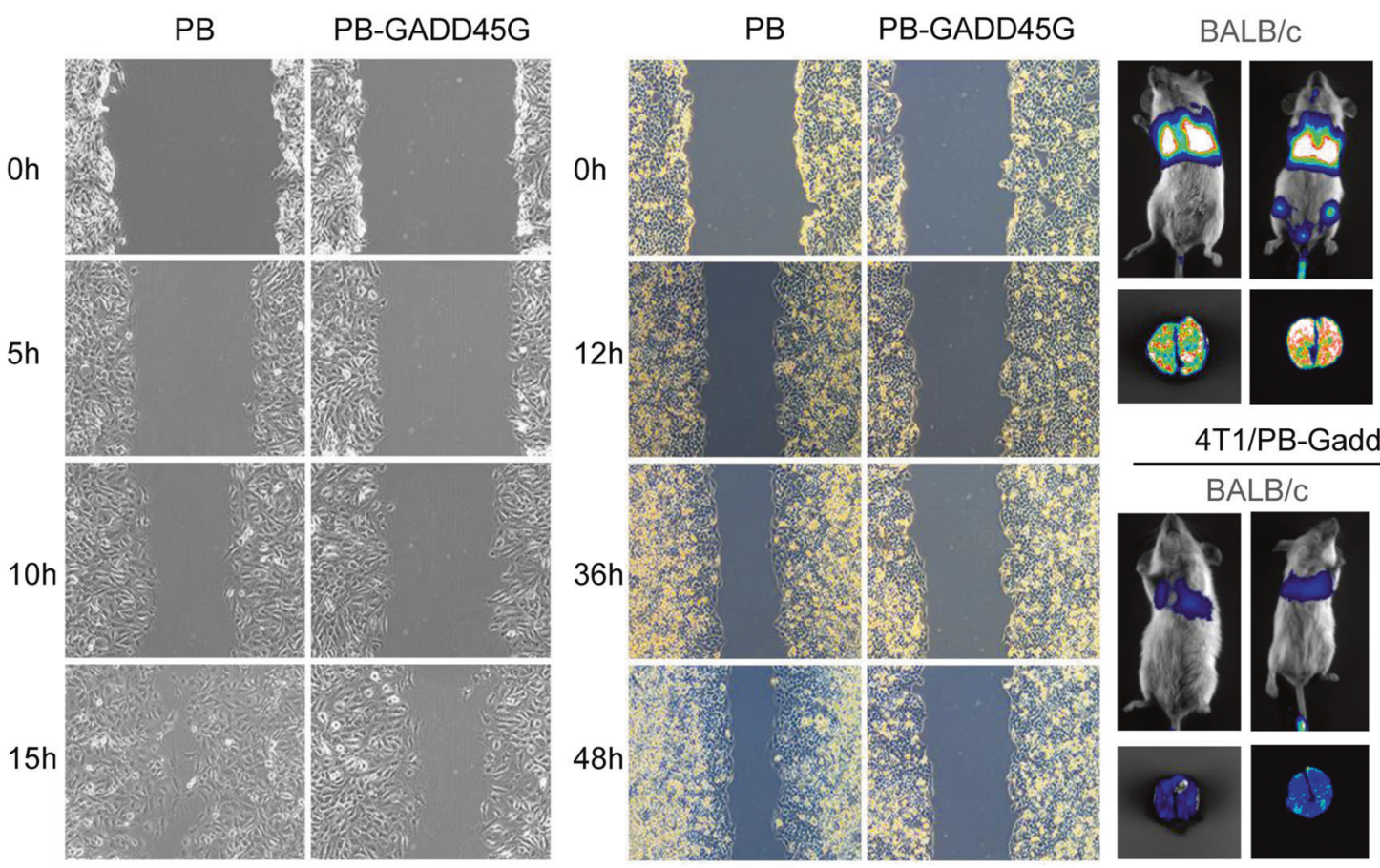

F
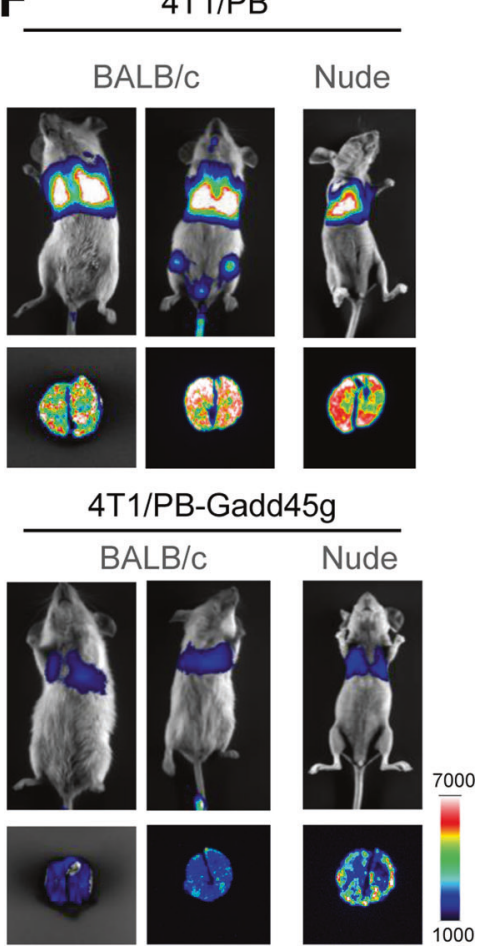

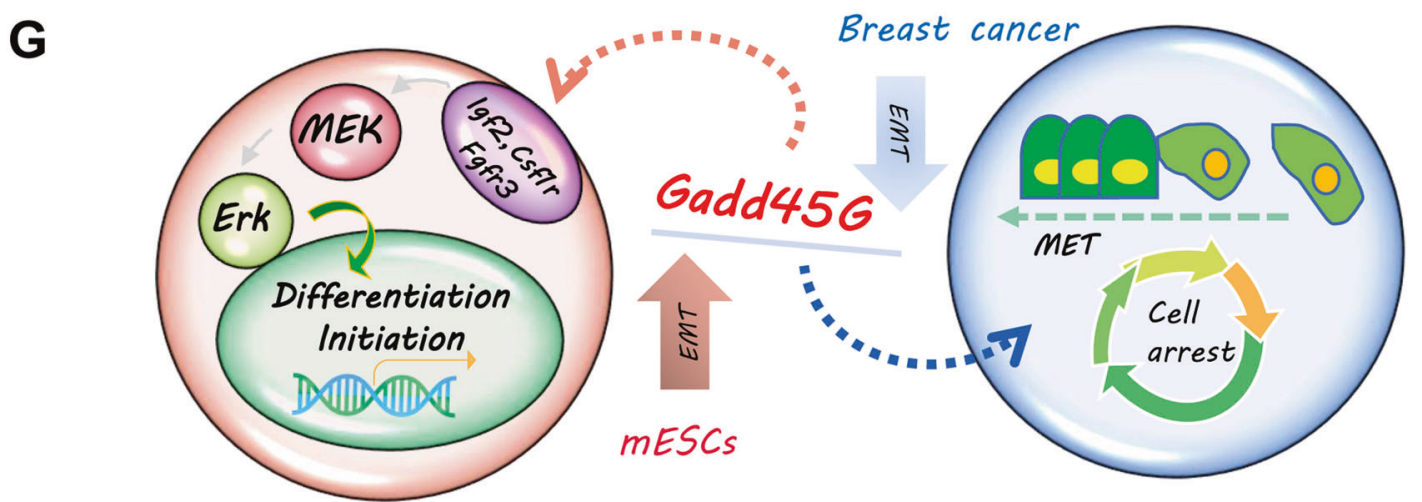

Fig. 6 Overexpression of GADD45G decreases the migration of breast cancer cells. A, B Western blot analysis of E-cadherin and N-cadherin levels in MCF7 or Hs578T cells overexpressing PB or PB-GADD45G. $\beta$-tubulin was used as a loading control. C Transwell experiments were used to analyze the migration ability of MCF7 and Hs578T cells overexpressing PB or PB-GADD45G. D, E The scratch experiments were used to evaluate the migration abilities of MCF7 or Hs578T cells overexpressing PB or PB-GADD45G. F Luciferase-tagged mouse breast cancer 4T1 cells stably expressing PB or PB-Gadd45g were transplanted in mice. Metastasis was imaged using Tanon-5200Multi system. G Schematic diagram of the role of Gadd45g in mouse ESCs and breast cancer cells. Overexpression of Gadd $45 \mathrm{~g}$ triggers ESC differentiation via activation of MAPK signaling, and suppresses the proliferation and invasion of breast cancer cells in vivo and in vitro. 
for $12-24 \mathrm{~h}$. After the ethanol was discarded, cells were stained with the reagents of the cell cycle and apoptosis detection kit (C1052, Beyotime Biotechnology, China) and were incubated at $37^{\circ} \mathrm{C}$ for $30 \mathrm{~min}$ in the dark. All samples were put on ice and were analyzed by flow cytometry instrument (BD bioscience) to detect the cell cycle changes.

\section{CCK8 assay}

Two thousands to five thousands cells were seeded in a 96-well plate at $37^{\circ} \mathrm{C}$. Cell Counting Kit-8 (CCK8) reagent was added every $12 \mathrm{~h}$ and cells were incubated for $1 \mathrm{~h}$ in the dark at $37^{\circ} \mathrm{C}$. The absorbance was measured at $450 \mathrm{~nm}$ in a microplate reader (Molecular Devices).

\section{Animal models}

Four- to five-week-old BALB/C or BALB/c-nude female mice were used in our experiments. For in vivo imaging technology, $2-5 \times 10^{6}$ cells carrying Luciferase (LUC) coding sequences were injected into mice. After 10-15 days, D-Luciferin potassium salt $(150 \mathrm{mg} / \mathrm{kg})(40902 \mathrm{ES} 02$, YEASEN, China) was injected into the abdominal cavity of anesthetized mice, the latter were placed in the Chemiluminescence Gel Imaging System Tanon5200Multi (Shanghai Tanon, China) to observe live imaging.

\section{Accession number}

Our Microarray dataset has been deposited in the GEO database under ID number GSE172474.

\section{Statistical analysis}

Mice with poor physical condition were excluded before grouping Quantitative data are representative of at least three biological replicates or three independent experiments. All data are reported as the mean \pm s.d., Student's $t$-test is used to determine the significance of the comparison difference by using GraphPad Prism 8 software. Values with $p<0.05$ are considered statistically significant. No animal randomization was used. No blinding was used. No statistical method was used to predetermine the sample size.

\section{DATA AVAILABILITY}

All the data generated or analyzed during this this study are included in this published article.

\section{REFERENCES}

1. Huang G, Ye S, Zhou X, Liu D, Ying QL. Molecular basis of embryonic stem cell self-renewal: from signaling pathways to pluripotency network. Cell Mol Life Sci. 2015;72:1741-1757.

2. Evans MJ, Kaufman MH. Establishment in culture of pluripotential cells from mouse embryos. Nature. 1981;292:154-156.

3. Martin GR. Isolation of a pluripotent cell line from early mouse embryos cultured in medium conditioned by teratocarcinoma stem cells. Proc Natl Acad Sci USA. 1981;78:7634-7638.

4. Smith AG, Heath JK, Donaldson DD, Wong GG, Moreau J, Stahl M, et al. Inhibition of pluripotential embryonic stem cell differentiation by purified polypeptides. Nature. 1988;336:688-690.

5. Williams RL, Hilton DJ, Pease S, Willson TA, Stewart CL, Gearing DP, et al. Myeloid leukaemia inhibitory factor maintains the developmental potential of embryonic stem cells. Nature. 1988;336:684-687.

6. Buehr M, Meek S, Blair K, Yang J, Ure J, Silva J, et al. Capture of authentic embryonic stem cells from rat blastocysts. Cell. 2008;135:1287-1298.

7. Ye S, Li P, Tong C, Ying QL. Embryonic stem cell self-renewal pathways converge on the transcription factor Tfcp2l1. EMBO J. 2013;32:2548-2560.

8. Martello G, Bertone $P$, Smith A. Identification of the missing pluripotency mediator downstream of leukaemia inhibitory factor. EMBO J. 2013;32:2561-2574.

9. Martello G, Sugimoto T, Diamanti E, Joshi A, Hannah R, Ohtsuka S, et al. Esrrb is a pivotal target of the Gsk3/Tcf3 axis regulating embryonic stem cell self-renewal. Cell Stem Cell. 2012;11:491-504.

10. Yeo JC, Jiang J, Tan ZY, Yim GR, Ng JH, Goke J, et al. Klf2 is an essential factor that sustains ground state pluripotency. Cell Stem Cell. 2014;14:864-872.

11. Ye S, Zhang D, Cheng F, Wilson D, Mackay J, He K, et al. Wnt/beta-catenin and LIFStat3 signaling pathways converge on Sp5 to promote mouse embryonic stem cell self-renewal. J Cell Sci. 2016;129:269-276.

12. Kim RJ, Nam JS. OCT4 expression enhances features of cancer stem cells in a mouse model of breast cancer. Lab Anim Res. 2011;27:147-152.
13. Lu X, Mazur SJ, Lin T, Appella E, Xu Y. The pluripotency factor nanog promotes breast cancer tumorigenesis and metastasis. Oncogene. 2014;33:2655-2664.

14. Lengerke C, Fehm T, Kurth R, Neubauer H, Scheble V, Muller F, et al. Expression of the embryonic stem cell marker SOX2 in early-stage breast carcinoma. BMC Cancer. 2011;11:42.

15. McConnell BB, Yang VW. Mammalian Kruppel-like factors in health and diseases. Physiol Rev. 2010;90:1337-1381.

16. Smith ML, Chen IT, Zhan Q, Bae I, Chen CY, Gilmer TM, et al. Interaction of the p53-regulated protein Gadd45 with proliferating cell nuclear antigen. Science. 1994;266:1376-1380.

17. Hollander MC, Sheikh MS, Bulavin DV, Lundgren K, Augeri-Henmueller L, Shehee $\mathrm{R}$, et al. Genomic instability in Gadd45a-deficient mice. Nat Genet. 1999;23:176-184.

18. Munoz-Najar U, Sedivy JM. Epigenetic control of aging. Antioxid Redox Signal. 2011;14:241-259.

19. Wang XW, Zhan Q, Coursen JD, Khan MA, Kontny HU, Yu L, et al. GADD45 induction of a G2/M cell cycle checkpoint. Proc Natl Acad Sci USA. 1999;96:3706-3711.

20. Harkin DP, Bean JM, Miklos D, Song YH, Truong VB, Englert C, et al. Induction of GADD45 and JNK/SAPK-dependent apoptosis following inducible expression of BRCA1. Cell. 1999;97:575-586.

21. Tamura RE, de Vasconcellos JF, Sarkar D, Libermann TA, Fisher PB, Zerbini LF. GADD45 proteins: central players in tumorigenesis. Curr Mol Med. 2012;12:634-651.

22. Hoffman B, Liebermann DA. Gadd45 modulation of intrinsic and extrinsic stress responses in myeloid cells. J Cell Physiol. 2009;218:26-31.

23. Fornace AJ Jr., Nebert DW, Hollander MC, Luethy JD, Papathanasiou M, Fargnoli J, et al. Mammalian genes coordinately regulated by growth arrest signals and DNA-damaging agents. Mol Cell Biol. 1989;9:4196-4203.

24. Abdollahi A, Lord KA, Hoffman-Liebermann B, Liebermann DA. Sequence and expression of a cDNA encoding MyD118: a novel myeloid differentiation primary response gene induced by multiple cytokines. Oncogene. 1991;6:165-167.

25. Beadling $\mathrm{C}$, Johnson KW, Smith KA. Isolation of interleukin 2-induced immediateearly genes. Proc Natl Acad Sci USA. 1993;90:2719-2723.

26. Schule KM, Leichsenring $M$, Andreani T, Vastolo V, Mallick $M$, Musheev $M U$, et al. GADD45 promotes locus-specific DNA demethylation and $2 \mathrm{C}$ cycling in embryonic stem cells. Genes Dev. 2019;33:782-798.

27. Sharov AA, Masui S, Sharova LV, Piao Y, Aiba K, Matoba R, et al. Identification of Pou5f1, Sox2, and Nanog downstream target genes with statistical confidence by applying a novel algorithm to time course microarray and genome-wide chromatin immunoprecipitation data. BMC Genomics. 2008;9:269.

28. Jung $M$, Peterson $H$, Chavez $L$, Kahlem $P$, Lehrach $H$, Vilo J, et al. A data integration approach to mapping OCT4 gene regulatory networks operative in embryonic stem cells and embryonal carcinoma cells. PLoS ONE. 2010;5:e10709.

29. Saxe JP, Tomilin A, Scholer HR, Plath K, Huang J. Post-translational regulation of Oct4 transcriptional activity. PLoS ONE. 2009;4:e4467.

30. Kaufmann LT, Gierl MS, Niehrs C. Gadd45a, Gadd45b and Gadd45g expression during mouse embryonic development. Gene Expr Patterns. 2011;11:465-470.

31. Johnen $H$, Gonzalez-Silva L, Carramolino L, Flores JM, Torres M, Salvador JM. Gadd $45 \mathrm{~g}$ is essential for primary sex determination, male fertility and testis development. PLoS ONE. 2013;8:e58751.

32. Huang HS, Kubish GM, Redmond TM, Turner DL, Thompson RC, Murphy GG, et al. Direct transcriptional induction of Gadd45gamma by Ascl1 during neuronal differentiation. Mol Cell Neurosci. 2010;44:282-296.

33. Thalheimer FB, Wingert $S$, De Giacomo $P$, Haetscher $N$, Rehage $M$, Brill $B$, et al. Cytokine-regulated GADD45G induces differentiation and lineage selection in hematopoietic stem cells. Stem Cell Rep. 2014;3:34-43.

34. Kaufmann LT, Niehrs C. Gadd45a and Gadd45g regulate neural development and exit from pluripotency in Xenopus. Mech Dev. 2011;128:401-411.

35. Kunath T, Saba-El-Leil MK, Almousailleakh M, Wray J, Meloche S, Smith A. FGF stimulation of the Erk $1 / 2$ signalling cascade triggers transition of pluripotent embryonic stem cells from self-renewal to lineage commitment. Development. 2007;134:2895-2902.

36. lacovino M, Bosnakovski D, Fey H, Rux D, Bajwa G, Mahen E, et al. Inducible cassette exchange: a rapid and efficient system enabling conditional gene expression in embryonic stem and primary cells. Stem Cells. 2011;29:1580-1588.

37. Zhang L, Yang Z, Ma A, Qu Y, Xia S, Xu D, et al. Growth arrest and DNA damage 45G down-regulation contributes to Janus kinase/signal transducer and activator of transcription 3 activation and cellular senescence evasion in hepatocellular carcinoma. Hepatology. 2014;59:178-189.

38. Zerbini LF, de Vasconcellos JF, Czibere A, Wang Y, Paccez JD, Gu X, et al. JunDmediated repression of GADD45alpha and gamma regulates escape from cell death in prostate cancer. Cell Cycle. 2011;10:2583-2591.

39. Ying J, Srivastava G, Hsieh WS, Gao Z, Murray P, Liao SK, et al. The stressresponsive gene GADD45G is a functional tumor suppressor, with its response to environmental stresses frequently disrupted epigenetically in multiple tumors. Clin Cancer Res. 2005;11:6442-6449. 
40. de la Calle-Mustienes E, Glavic A, Modolell J, Gomez-Skarmeta JL. Xiro homeoproteins coordinate cell cycle exit and primary neuron formation by upregulating neuronal-fate repressors and downregulating the cell-cycle inhibitor XGadd45gamma. Mech Dev. 2002;119:69-80.

41. Candal E, Thermes V, Joly JS, Bourrat F. Medaka as a model system for the characterisation of cell cycle regulators: a functional analysis of OlGadd45gamma during early embryogenesis. Mech Dev. 2004;121:945-958.

42. Ying QL, Nichols J, Chambers I, Smith A. BMP induction of Id proteins suppresses differentiation and sustains embryonic stem cell self-renewal in collaboration with STAT3. Cell. 2003;115:281-292.

43. Lu Y, Liang M, Zhang Q, Liu Z, Song Y, Lai L, et al. Mutations of GADD45G in rabbits cause cleft lip by the disorder of proliferation, apoptosis and epithelial-mesenchymal transition (EMT). Biochim Biophys Acta Mol Basis Dis. 2019;1865:2356-67.

44. Chen T, You Y, Jiang H, Wang ZZ. Epithelial-mesenchymal transition (EMT): a biological process in the development, stem cell differentiation, and tumorigenesis. J Cell Physiol. 2017;232:3261-3272.

45. Eastham AM, Spencer H, Soncin F, Ritson S, Merry CL, Stern PL, et al. Epithelialmesenchymal transition events during human embryonic stem cell differentiation. Cancer Res. 2007;67:11254-11262.

46. Spencer HL, Eastham AM, Merry CL, Southgate TD, Perez-Campo F, Soncin F, et al. E-cadherin inhibits cell surface localization of the pro-migratory $5 \mathrm{~T} 4$ oncofetal antigen in mouse embryonic stem cells. Mol Biol Cell. 2007;18:2838-2851.

47. Kim YS, Yi BR, Kim NH, Choi KC. Role of the epithelial-mesenchymal transition and its effects on embryonic stem cells. Exp Mol Med. 2014;46:e108.

48. Guo WT, Wang XW, Yan YL, Li YP, Yin X, Zhang Q, et al. Suppression of epithelialmesenchymal transition and apoptotic pathways by miR-294/302 family synergistically blocks let-7-induced silencing of self-renewal in embryonic stem cells. Cell Death Differ. 2015;22:1158-1169.

49. Levenstein ME, Ludwig TE, Xu RH, Llanas RA, VanDenHeuvel-Kramer K, Manning $D$, et al. Basic fibroblast growth factor support of human embryonic stem cell selfrenewal. Stem Cells. 2006;24:568-574.

50. Guo W, Dong Z, Guo Y, Chen Z, Kuang G, Yang Z. Methylation-mediated repression of GADD45A and GADD45G expression in gastric cardia adenocarcinoma. Int J Cancer. 2013;133:2043-2053.

51. Li T, Xu L, Teng J, Ma Y, Liu W, Wang Y, et al. GADD45G interacts with E-cadherin to suppress the migration and invasion of esophageal squamous cell carcinoma. Dig Dis Sci. 2020;65:1032-1041.

52. Zhang $H$, Xiong $Y$, Beach $D$. Proliferating cell nuclear antigen and p21 are components of multiple cell cycle kinase complexes. Mol Biol Cell. 1993;4:897-906.

53. Ishida K, Yuge Y, Hanaoka M, Yasukawa M, Minami Y, Ogawa M, et al. Gadd45g regulates dental epithelial cell proliferation through p38 MAPK-mediated p21 expression. Genes Cells. 2013;18:660-671.

54. Vairapandi M, Balliet AG, Fornace AJ Jr., Hoffman B, Liebermann DA. The differentiation primary response gene MyD118, related to GADD45, encodes for a nuclear protein which interacts with PCNA and p21WAF1/CIP1. Oncogene. 1996;12:2579-2594.

55. Zhan Q, Antinore MJ, Wang XW, Carrier F, Smith ML, Harris CC, et al. Association with $\mathrm{Cdc} 2$ and inhibition of $\mathrm{Cdc} 2 / \mathrm{Cyclin} \mathrm{B} 1$ kinase activity by the p53-regulated protein Gadd45. Oncogene. 1999;18:2892-2900.

56. Jin S, Tong T, Fan W, Fan F, Antinore MJ, Zhu X, et al. GADD45-induced cell cycle G2-M arrest associates with altered subcellular distribution of cyclin B1 and is independent of p38 kinase activity. Oncogene. 2002;21:8696-8704.

57. Jackson JG, Pereira-Smith OM. p53 is preferentially recruited to the promoters of growth arrest genes p21 and GADD45 during replicative senescence of normal human fibroblasts. Cancer Res. 2006;66:8356-8360.

58. Mo Q, Xu K, Luo C, Zhang Q, Wang L, Ren G. BTNL9 is frequently downregulated and inhibits proliferation and metastasis via the P53/CDC25C and P53/GADD45 pathways in breast cancer. Biochem Biophys Res Commun. 2021;553:17-24.

59. Bartholomeusz C, Gonzalez-Angulo AM, Liu P, Hayashi N, Lluch A, Ferrer-Lozano J, et al. High ERK protein expression levels correlate with shorter survival in triplenegative breast cancer patients. Oncologist. 2012;17:766-774.

60. Mirzoeva OK, Das D, Heiser LM, Bhattacharya S, Siwak D, Gendelman R, et al. Basal subtype and MAPK/ERK kinase (MEK)-phosphoinositide 3-kinase feedback signaling determine susceptibility of breast cancer cells to MEK inhibition. Cancer Res. 2009;69:565-572.

\section{ACKNOWLEDGEMENTS}

We thank Qi-Long Ying (University of Southern California, USA) for providing the $46 \mathrm{C}$ $\mathrm{mESCs}$ and Michael Kyba (University of Minnesota, USA) for providing the ICE inducible system.

\section{AUTHOR CONTRIBUTIONS}

$X Z$ and $X X W$ conceived the study, $X Z, J$, and $Y L$ designed all experiments and analyzed the data, $X W, M Z, X L, Y Z$, and $Z Z$ assisted in the analysis and interpretation of experiments, SY supervised the project. $X Z, X X W$, and SY wrote the manuscript.

\section{FUNDING INFORMATION}

This work was supported by the Natural Science Foundation of Anhui Province [1908085J13], the Key Research and Development Project of Anhui Province [202104b11020026], the University Synergy Innovation Program of Anhui Province [GXXT-2020-064], the Open Fund for Discipline Construction, Institute of Physical Science and Information Technology, Anhui University [S01003106], and the Funding supported by the Department of Education of Anhui Province and the Department of Human Resources and Social Security of Anhui Province (gxyqZD2020001, 2020H210).

\section{COMPETING INTERESTS}

The authors declare no competing interests.

\section{ETHICS APPROVAL AND CONSENT TO PARTICIPATE}

No experiments involving human subjects were performed during this study. All animal experiments were conducted in accordance with an approved protocol and carried out according to the institutional animal welfare guidelines of the Anhui University (Protocol No: 2021-029).

\section{ADDITIONAL INFORMATION}

Supplementary information The online version contains supplementary material available at https://doi.org/10.1038/s41420-021-00667-x.

Correspondence and requests for materials should be addressed to Shou-Dong Ye or Xiaoxiao Wang.

Reprints and permission information is available at http://www.nature.com/ reprints

Publisher's note Springer Nature remains neutral with regard to jurisdictional claims in published maps and institutional affiliations.

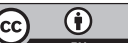

Open Access This article is licensed under a Creative Commons Attribution 4.0 International License, which permits use, sharing, adaptation, distribution and reproduction in any medium or format, as long as you give appropriate credit to the original author(s) and the source, provide a link to the Creative Commons license, and indicate if changes were made. The images or other third party material in this article are included in the article's Creative Commons license, unless indicated otherwise in a credit line to the material. If material is not included in the article's Creative Commons license and your intended use is not permitted by statutory regulation or exceeds the permitted use, you will need to obtain permission directly from the copyright holder. To view a copy of this license, visit http://creativecommons. org/licenses/by/4.0/.

(c) The Author(s) 2021 